\title{
Evaluation of Cloud Parameterizations in a High Resolution Atmospheric General Circulation Model using ARM Data
}

\author{
B. Govindasamy, P. Duffy
}

\section{April 12, 2002}

U.S. Department of Energy

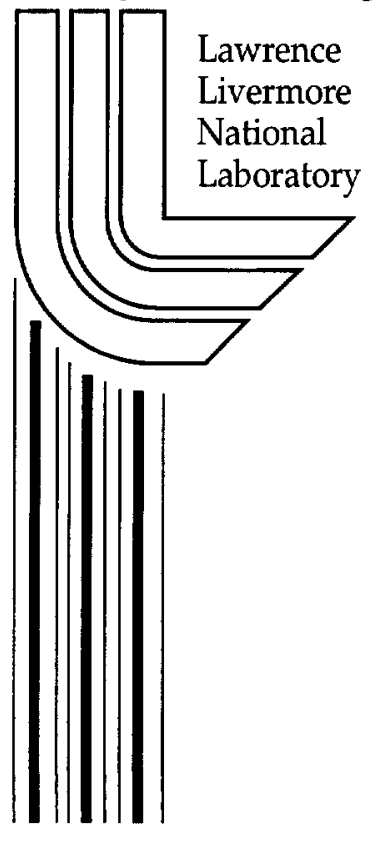




\section{DISCLAIMER}

This document was prepared as an account of work sponsored by an agency of the United States Government. Neither the United States Government nor the University of California nor any of their employees, makes any warranty, express or implied, or assumes any legal liability or responsibility for the accuracy, completeness, or usefulness of any information, apparatus, product, or process disclosed, or represents that its use would not infringe privately owned rights. Reference herein to any specific commercial product, process, or service by trade name, trademark, manufacturer, or otherwise, does not necessarily constitute or imply its endorsement, recommendation, or favoring by the United States Government or the University of California. The views and opinions of authors expressed herein do not necessarily state or reflect those of the United States Government or the University of California, and shall not be used for advertising or product endorsement purposes.

This work was performed under the auspices of the U. S. Department of Energy by the University of California, Lawrence Livermore National Laboratory under Contract No. W-7405-Eng-48.

This report has been reproduced directly from the best available copy.

Available electronically at http://www.doc.gov/bridge

Available for a processing fee to U.S. Department of Energy

And its contractors in paper from

U.S. Department of Energy

Office of Scientific and Technical Information

P.O. Box 62

Oak Ridge, TN 37831-0062

Telephone: (865) 576-8401

Facsimile: (865) 576-5728

E-mail: reports@adonis.osti.gov

Available for the sale to the public from

U.S. Department of Commerce

National Technical Information Service

5285 Port Royal Road

Springfield, VA 22161

Telephone: (800) 553-6847

Facsimile: (703) 605-6900

E-mail: orders@ntis.fedworld.gov

Online ordering: http://www.ntis.gov/ordering.htm

OR

Lawrence Livermore National Laboratory

Technical Information Department's Digital Library

http://www.llnl.gov/tid/Library.html 


\title{
Evaluation of Cloud Parameterizations in a High Resolution Atmospheric General Circulation Model using ARM data
}

\author{
Proposal Submitted to the DOE Atmospheric Radiation Measurement Program \\ Program Announcement LAB 02-07
}

by

Lawrence Livermore National Laboratory

Livermore, CA

Principal Investigator:

Dr. Bala Govindasamy, PI

Research Scientist

Atmospheric Sciences Division

Energy and Environment Directorate

Lawrence Livermore National Laboratory

Mail Stop L-103

P.O. Box 808, 7000 East Avenue

Livermore, CA 94550

Tel: (925) 423-0771

Fax: (925) 422-6388

Email: bala@Ilnl.gov
Co Investigator: Dr. Philip Duffy Research Scientist

Atmospheric Sciences division Energy and Environment Directorate Lawrence Livermore National Laboratory Mail Stop L-103

P. O. Box 808, 7000 East Avenue Livermore, CA 94550

Tel: (925) 422-3722

Fax: (925) 422-6388

Email: duffy2@llnl.gov

Budget:

FY 2003: $\$ \underline{225,000}$ FY2004: $\$ \underline{240,000}$ FY2005: $\$ \underline{255,000}$ Total: $\$ \underline{720,000}$

Use of human subjects or vertebrate animals in proposed project: NO

G. Balasuhramanar 4/12/02

Dr. Bala Govindasamy Date

Research Scientist

Atmospheric Science Division

Energy and Environment Directorate

Lawrence Livermore National Laboratory

Tel: (925) 423-4191

Fax: (925) 422-6388

Email: caldeira2@llnl.gov

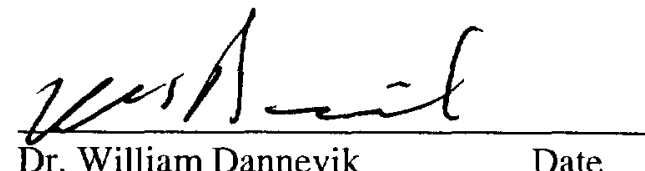

Division Leader

Atmospheric Science Division

Energy and Environment Directorate

Lawrence Livermore National Laboratory

Tel: (925) 422-3132

Fax: (925) 423-4908

Email: dannevik1@Ilnl.gov

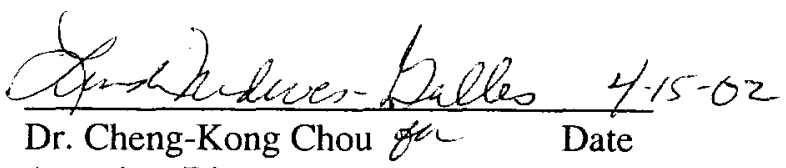

Associate Director

Energy and Environment Directorate

Lawrence Livermore National Laboratory

Tel: (925) 422-4950

Fax: (925) 422-0096

Email: chou1@llnl.gov 


\section{PROPOSAL FOR LAB 02-07: EVALUATION OF CLOUD PARAMETERIZATION}

started using ARM data with the purpose of validating and improving physics parameterizations in the NCAR AGCM. The approach used is called Initial Tendency Error Analysis (ITEA). In this dynamical approach, the climate model will be used in a weather forecast mode to see how quickly it drifts from the observed weather and detailed observations provided by the ARM program. By contrast, our approach to validating the parameterizations will be a statistical one and it will focus on clouds and radiation and use high-resolution climate modeling. We will collaborate with PCMDI since the overall goal of our project and PCMDI's ITEA is the same; improving physics parameterization in NCAR AGCM.

20 e. Approach

Our approach to validating the GCM parameterizations will be a statistical one and it will focus on clouds and radiation. We will use high-resolution (T85 and T239) climate modeling.

20 g. Future accomplishments

We propose to fulfill our plan on schedule and within budget

20 k. Deliverables

(1) Form a cloud and radiation climatology for the ARM CART sites. The cloud statistics will consist of daily and monthly means of clouds at all levels in the vertical, cloud base height, cloud depth, and cloud liquid water. Daily and monthly means of shortwave and longwave fluxes at the surface and top of the atmosphere will be also formed. This climatology will be made available to the public so that GCM modelers can readily evaluate the cloud climatology of their models against ARM observations.

(2) Evaluate the cloud statistics of NCAR's Community Atmosphere Model (CAM) at resolution T85. Model deficiencies and biases will be identified. The causes for the deviation of the simulated results from ARM observations will be investigated. We will then modify the parameters in clouds and convection parameterization in CAM at T85 so that the model results are in better agreement with observations. The reason for choosing T85 is that the climate modeling community is starting to make the transition from T42 to T85.

(3) Evaluate the cloud statistics of CAM at resolution T239. We propose to produce a well 'tuned' T239 that will be a valuable tool to understand regional climate change. 


\section{Evaluation of Cloud Parameterizations in a High Resolution Atmospheric General Circulation Model using ARM data}

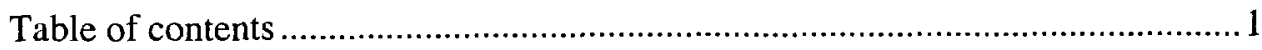

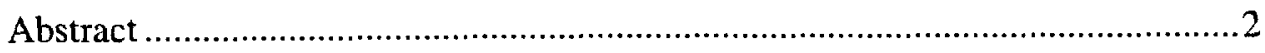

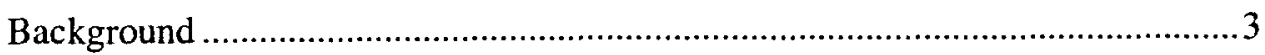

Advantages of high resolution climate modeling ...................................... 3

Resolution dependence of parameterization ........................................... 4

Validation of climate models using ARM data .....................................

The ARM program and clouds ...........................................................

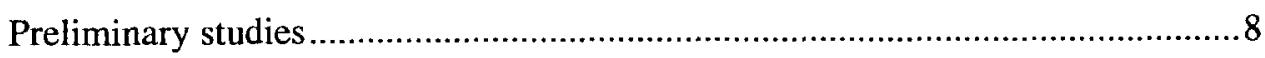

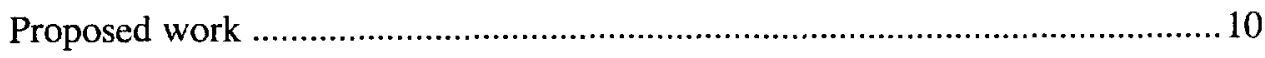

Summary description of proposed work ............................................. 10

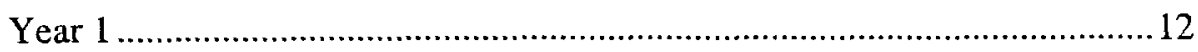

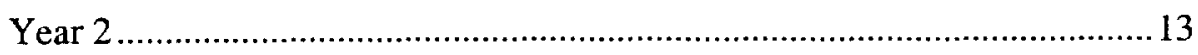

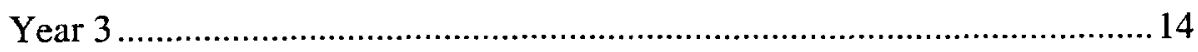

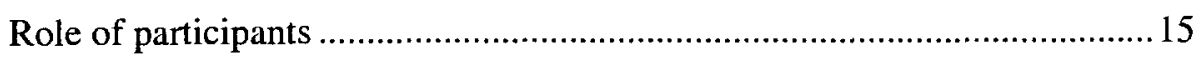

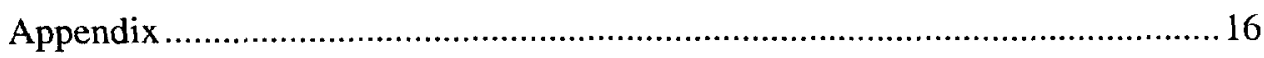

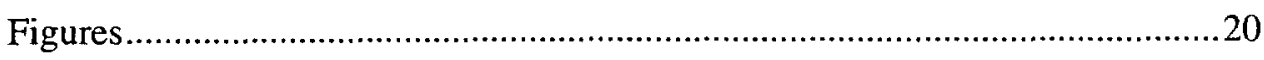

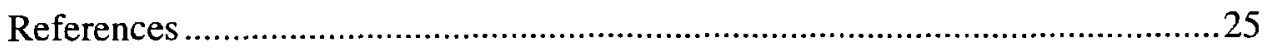

Budget and budget justification

Other support of investigators

Biographical sketches

Description of facilities and resources

Letters of Support 
PROPOSAL FOR LAB 02-07: EVALUATION OF CLOUD PARAMETERIZATION

\title{
Evaluation of Cloud Parameterizations in a High Resolution Atmospheric General Circulation Model using ARM data
}

\begin{abstract}
Typical state of the art atmospheric general circulation models used in climate change studies have horizontal resolution of approximately $300 \mathrm{~km}$. As computing power increases, many climate modeling groups are working toward enhancing the resolution of global models. An important issue that arises when resolution of a model is changed is whether cloud and convective parameterizations, which were developed for use at coarser resolutions, will need to be reformulated or re-tuned. We propose to investigate this issue and specifically cloud statistics using ARM data. The data streams produced by highly instrumented sections of Cloud and Radiation Testbeds (CART) of ARM program will provide a significant aid in the evaluation of cloud and convection parameterization in high-resolution models.

Recently, we have performed multiyear global-climate simulations at T170 and T239 resolutions, corresponding to grid cell sizes of $0.7^{0}$ and $0.5^{0}$ respectively, using the NCAR Community Climate Model. We have also a performed climate change simulation at T170. On the scales of a T42 grid cell $(300 \mathrm{~km})$ and larger, nearly all quantities we examined in T170 simulation agree better with observations in terms of spatial patterns than do results in a comparable simulation at $\mathrm{T} 42$. Increasing the resolution to $\mathrm{T} 239$ brings significant further improvement.

At T239, the high-resolution model grid cells approach the dimensions of the highly instrumented sections of ARM Cloud and Radiation Testbed (CART) sites. We propose to form a cloud climatology using ARM data for its CART sites and evaluate cloud statistics of the NCAR Community Atmosphere Model (CAM) at higher resolutions over those sites using this ARM cloud climatology. We will then modify the physical parameterizations of CAM for better agreement with ARM data. We will work closely with NCAR in modifying the parameters in cloud and convection parameterizations for the high-resolution model. Our proposal to evaluate the cloud parameterization at high resolution has high relevance for the mission of ARM (to improve the treatment of clouds and radiation in the models) because the high-resolution model grid cells approach the dimensions of the highly instrumented sections of ARM CART sites.
\end{abstract}




\section{Evaluation of Cloud Parameterizations in a High Resolution Atmospheric General Circulation Model using ARM data}

\section{Background}

\subsection{Advantages of high resolution climate modeling}

Typical state of the art Atmospheric General Circulation models used in climate change studies have approximately $300 \mathrm{~km}$ resolution in the horizontal. As computing power increases, many climate modeling groups are working toward the possibility of enhancing the resolution of global models. In principle, high resolution models have several advantages: 1) the dynamics is better resolved; 2) topography and the land sea mask are better resolved compared to their coarse resolution counterparts; 3) more physical processes can be explicitly represented, reducing dependence on semi-empirical parameterizations; 4) with a high resolution model, regional spatial scale details are simulated and hence prediction of regional climate change becomes more credible; 5) because high resolution models simulate a wider spectrum of spatial scales and their nonlinear interactions, in principle, even the larger scale features should be better simulated by them. This was found to be the case by Williamson (1999) and Duffy et al. (2002). Higher resolution global models have the added advantage over regional models that they avoid the numerical problems associated with lateral boundary conditions. They also avoid the scale separation issues that are faced by regional models driven by coarse resolution global models.

In the past, many studies (e.g. Manabe et al,, 1970; Wellck et al., 1971; Rind, 1988; Tibaldi et al., 1990; Boville, 1991; Kiehl and Williamson, 1991; Boyle, 1993; Gleckler and Taylor, 1993; Sperber et al., 1994; Williamson et al., 1995; Phillips et al., 1995; Boer and Denis, 1997; Williamson, 1999) have investigated the influence of horizontal resolution on the simulated climate. The broad conclusions are: 1) many climate statistics show a monotonic signal with increasing resolution, with the largest variation occurring from low (R15 or T21) to medium 


\section{PROPOSAL FOR LAB 02-07: EVALUATION OF CLOUD PARAMETERIZATION}

resolution (T42 or T63). 2) The monotonic signal is often towards the atmospheric analyses, and in some cases, it continues beyond the highest simulation performed. 3) The highest resolution simulations are not the best by all measures. The lack of improvement at the finer resolutions may well be due to poor performance of parameterizations at these resolutions. Therefore, these studies indicate the need for careful evaluation of GCM parameterizations at fine resoultions.

Recently, we have performed the first ever multiyear simulations of present day climate at T170 and T239 resolutions corresponding to grid cell sizes of $0.7^{\circ}$ and $0.5^{\circ}$ respectively, using the NCAR Community Climate Model (Duffy et al., 2002; Govindasamy et al., 2002). On the scales of a T42 grid cell and larger, nearly all quantities we examined in the T170 simulations agree better with observations in terms of spatial patterns than a comparable simulation at T42. In some cases, the improvements were substantial. Significant further improvement occurs when the resolution is increased from $\mathrm{T} 170$ to $\mathrm{T} 239$. We also performed climate change calculations at T170. Here, regional climate change features were substantially different at T170 from a comparable simulation at $\mathrm{T} 42$.

\subsection{Resolution dependence of parameterization}

An important issue that arises when resolution of a model is changed is whether parameterizations of clouds, convection, radiation, planetary boundary layer, which were developed for use at coarser resolutions, will need to be reformulated or re-tuned. Consider the impact of unresolved eddies (which are parameterized as diffusion) on the large scale motion. As the resolution becomes finer, the size of the largest unresolved eddies decreases. The eddy viscosity coefficient should be chosen such that the simulated energy spectrum of atmosphere is unaffected by the resolution change.

As a simple example, consider the decrease in time step when the resolution is increased. Unless we change the convective time scale in the parameterization of convection, the partition between large scale and convective precipitation will change because the large-scale stable rain makes a complete thermodynamic adjustment in a single time step. As an alternate example, 
PROPOSAL FOR LAB 02-07: EVALUATION OF CLOUD PARAMETERIZATION

consider the minimum relative humidity for cloud formation. From the current coarse resolution $(\sim 300 \mathrm{~km})$ to the limit of cloud scale resolution $(\sim 10 \mathrm{~km})$, the threshold relative humidity should increase from approximately $80 \%$ to $100 \%$ for physical consistency. Also, the minimum vertical velocity for cloud formation should increase with resolution as the aspect ratio of the grid boxes increases with increases in horizontal resolution. Total column convective cloud amount is not allowed to exceed $80 \%$ at T42 in the NCAR CCM3. As the resolution of the model is increased, this maximum convective cloud amount should be increased and it should be $100 \%$ when the grid size approaches the convective cloud scale $(\sim 10 \mathrm{~km})$.

The resolution dependence of cloud properties for the NCAR community model was examined by Kiehl and Williamson (1991) for a range of resolutions from R15 to T106. They found a systematic decrease in simulated cloud amount with increasing resolution; they argue that this effect is a result of increased subsidence at finer resolutions; this results in advective drying, and thus less cloud. The increased subsidence in turn results from increased upward mass flux in the equatorial region. They argue that since the reduction in cloud amount at finer resolutions results from advective drying, any cloud parameterization (or at least any one in which less moisture results in less cloud) will produce the same effect. With the ECMWF (cycle 33) model, Phillips et al. (1995) found that moist processes (convection, cloudiness, and precipitation) have strong dependence on horizontal resolution.

In cloud and convection parameterization schemes used in the NCAR atmospheric general circulation model, there are many complex parameters like convective time scale, CAPE (Convective Available Potential Energy) consumption rate, minimum large scale velocity for cloud formation, minimum static stability, relative humidity threshold for cloud formation, maximum convective cloud amount, auto conversion rate for cloud liquid water to rain water, entrainment and detrainment rates of water vapor in and out of clouds, cloud liquid water at the base of the clouds, profile of liquid water content inside the clouds, effective cloud and ice particle radius, etc. These parameters are "tuned" in most models for a horizontal resolution of 
PROPOSAL FOR LAB 02-07: EVALUATION OF CLOUD PARAMETERIZATION

approximately $300 \mathrm{~km}$ so that the global mean and large scale features simulated by the model are close to observations.

\subsection{Validation of Climate Models using ARM Data}

A tuning approach based on the global averages and large-scale patterns has been used by GCM modelers (Williamson et al., 1995) because any other approach would be prohibitively expensive. However, this approach is not entirely satisfactory if GCMs are to be used for predicting regional climate change. An inexpensive method to evaluate GCM parameterization is to test the physics schemes outside the climate model. There are two approaches in this method, the semi-prognostic test and Single Column Modeling (SCM). In semi-prognostic approach (Lord, 1982; Kao and Ogura, 1987; and Grell et all., 1991), observations are used to prescribe the state of single GCM column and tendencies due to all processes except those associated with the parameterization to be tested. An SCM (Betts and Miller, 1986; Randall et al., 1996; Ghan et al., 2000; Cederwall et al., 2000) normally consists of full column physics of a GCM and it tests the full suite of parameteriations. The advection tendency and the boundary condition for the column are provided by observations (e.g. ARM data). The model calculates the physics tendencies. After a short period of time, the SCM predictions are compared against observations. Although SCMs have been used for improving the cloud and radiation parameterization over a decade, their utility to improve the parameterizations for GCMs have been limited because SCMs lack the feed back between the physics and dynamics that is operative in a GCM; SCMs are overly constrained by the observations. The semi-prognostic approach also lacks the feedback between dynamics and physics.

An alternate approach is to test the full GCM, not just a column, over a small region where high-density climate data is available. Although this approach is computationally expensive, it allows the feed back between dynamics and physics to operate in the model. Our experience with high-resolution modeling shows that today's computing power does allow us to evaluate the physics parameterization inside the GCM. As discussed in the next section, the 


\section{PROPOSAL FOR LAB 02-07: EVALUATION OF CLOUD PARAMETERIZATION}

Cloud and Radiation Testbed (CART) sites of the ARM program provide continuous data streams that could be used for this purpose. However, at coarse resolution (T42), only one gid cell of a GCM would cover the heavily instrumented ARM CART site. Evaluation of climate statistics over a single grid cell poses severe limitations for improving a climate model. On the other hand, the high-resolution model grid cells approach the dimensions of the highly instrumented sections of ARM CART sites. For instance, the CART site in Southern Great Plains (SGP) consists of in situ and remote-sensing instrument clusters arrayed across approximately 55,000 square miles or 140,800 square kilometers. Approximately 25 grid cells of T170 and 50 grid cells of T239 can be fitted over this region. Climate statistics computed and validated over multiple grid cells can provide valuable insight into the parameterizations in a GCM. A novel approach would be to compare cloud and radiation statistics over this region as simulated by the model against ARM observations and then modify convection and cloud parameters of GCM for better agreement with observations.

\subsection{The ARM program and Clouds}

This project would focus on cloud statistics because cloud feed backs are one of the most important, but also one of the least understood in climate change studies. Clouds affect the radiation budget of the planet by absorbing, scattering and emitting radiation. In an intercomparison of 14 atmospheric general circulation models, Cess et al. (1989) found that most of the variation in global climate sensitivity (the equilibrium surface temperature change to a doubling of atmospheric concentration of $\mathrm{CO}_{2}$ ) is attributable to differences in model's depictions of cloud-climate feedbacks. They emphasis the need for improvements in the treatment of clouds in climate models if they are to be used as climate predictors.

In 1989, therefore, DOE created the ARM program to improve the treatment of radiation and clouds in climate models, particularly the general circulation models used to predict future climate. The ARM program is an experimental testbed to gather data for the study of terrestrial radiation, properties of clouds, and life cycle of clouds. The ARM program has established and 
operates field research sites, called Cloud and Radiation Testbeds (CARTs), to study the effects of clouds on global climate change. ARM has CART sites at three primary locations- Southern Great Plains (SGP), Tropical Western Pacific (TWP), and North Slope of Alaska (NSA) identified as the range of climate conditions that should be studied. Each CART site is heavily instrumented to gather massive amounts of data.

As discussed above, ARM data has been mostly used to evaluate parameterization of clouds and radiation within SCM framework (Randall et al., 1996; Ghan et al., 2000; Cederwall et al., 2000). Recently, the Program for Climate Model Diagnosis and Intercomparison (PCMDI) at LLNL has started using ARM data for the purpose of validating and improving physics parameterizations in the NCAR AGCM. The approach used is called Initial Tendency Error Analysis (ITEA). In this dynamical approach, the climate model will be used in a weather forecast mode to see how quickly it drifts from the observed weather and detailed observations provided by the ARM program. By contrast, our approach to validating the parameterizations will be a statistical one and it will focus on clouds and radiation and use high-resolution climate modeling. We will collaborate with PCMDI, since the overall goal of our project and PCMDI's ITEA is the same: improving physics parameterization in NCAR AGCM.

\section{Preliminary Studies - Our experience with High-Resolution Modeling}

In the past 18 months, a series of climate simulations has been performed at LLNL using several high-resolution configurations of the NCAR CCM3 atmospheric climate model. Since the results of these simulations have not yet been published in the peer-reviewed literature, we provide here a brief description of the simulations and results.

All simulations were performed with the version 3.10 .11 "366 physics" of the NCAR Community Climate Model (CCM). All simulations were forced with prescribed sea-surface temperatures (SSTs) and sea ice concentrations. Five extended high-resolution climate simulations have been performed so far: 


\section{PROPOSAL FOR LAB 02-07: EVALUATION OF CLOUD PARAMETERIZATION}

1. A 12-year simulation of present climate at T170 truncation $(512 \times 256$ grid cells). This was forced with observed climatological monthly-mean SSTs and sea ice concentrations.

2. A 12-year simulation of effects of increased greenhouse gases at T170 truncation (Govindasamy et al., 2002). This was forced with SSTs obtained from a transient climate simulation with the NCAR CSM coupled model. From the coupled model results we calculated an SST perturbation by subtracting SSTs from the decade 1991-2000 from SSTs from the decade 2091-2100. The model was forced with SSTs obtained by adding this SST perturbation to climatological observed SSTs.

3. An AMIP simulation at T239 truncation (720x360 grid cells). This is forced with monthlymean SSTs observed during 1979-1985. This is the highest-resolution global climate simulation ever undertaken. 6 simulated years have been completed so far.

4. The above simulations were performed without re-"tuning" the model for high resolution (i.e. with a model tuned for T42). In collaboration with J.J. Hack at NCAR, we performed a firstorder re-tuning of the model physics at T170 truncation. We changed parameters related to clouds, such as relative humidity threshold for mid- and high-level cloud formation, cloud base liquid water, vertical profile of cloud liquid water. The untuned T170 model simulated excessive precipitation and outgoing longwave radiation. Therefore, we reduced the drag coefficient for evaporation over ocean (to correct global mean precipitation) and relative humidity threshold for mid- and high-level cloud formation (to increase the high level cloud fraction and reduce the outgoing longwave radiation). We recently completed a second simulation of the present climate at T170 with the re-tuned model. This partial retuning process very effectively removed biases (errors in mean quantities) seen in the untuned model. There was also some significant improvement in the spatial pattern of many simulated fields due to the retuning.

5. The parameter changes for tuning T170 were also adapted for T239 for eliminating the bias in precipitation and energy budgets at the surface and top of the atmosphere. We have 


\section{PROPOSAL FOR LAB 02-07: EVALUATION OF CLOUD PARAMETERIZATION}

performed 2 years of "tuned" T239 simulations using climatological SST and sea ice concentrations. (Results have not yet been completely analyzed, so some T239 results shown here are from the un-tuned T239 model)

In addition to these climate-length simulations, we have performed shorter simulations ( 1 month) at T340 truncation.

The results from our high-resolution climate modeling work are discussed in Appendix.

\section{Proposed Work}

\subsection{Summary Description of Proposed Work}

The major goals of the proposed work are (1) to use cloud and radiation statistics obtained from the ARM program to evaluate an atmospheric general circulation model at highresolution; (2) to improve cloud statistics as simulated by the climate model by modifying the cloud and convection parameterizations in the model. Since the size of grid cells of highresolution approach the highly instrumented sections of CART sites of ARM program, comparison of cloud statistics becomes more meaningful with high-resolution models.

We plan to use three resolutions, T42, T85 and T239, for this study. T42 is the standard configuration (grid size of $\sim 300 \mathrm{~km}$ ) currently used by climate modeling community. T42 will be the control resolution for our experiments. Cloud statistics as simulated by $\mathrm{T} 42$ will be compared against ARM observations and the deficiencies will be identified. The reason for choosing $\mathrm{T} 85$ is that the climate modeling community is starting to make the transition from T42 to T85. Our project will assist this transition by evaluating the physics parameterizations in the T85 model using ARM data. Looking farther into the future of global and regional climate modeling, we also plan to evaluate the cloud statistics of T239 and improve its performance using ARM data. At $\mathrm{T} 239\left(0.5^{\circ}\right.$ in latitude and longitude resolution), the global model resolution approaches the typical resolution of regional and Numerical Weather Prediction (NWP) models and the dimensions of the highly instrumented sections of CART sites of ARM. A well "tuned" model of 
PROPOSAL FOR LAB 02-07: EVALUATION OF CLOUD PARAMETERIZATION

such high resolution will be a valuable tool for the climate modeling community to understand regional climate change.

We propose to undertake this research in three stages. In the first stage, we will collect the observational date related to clouds and radiation produced by the ARM program. Conventional meteorological products such as temperature, specific humidity, zonal and meridional winds, omega, and time tendencies for temperature and water vapor are available at 3hr intervals for SGP site from ARM data infrastructure team at LLNL. In addition, many physics quantities such as precipitation, sensible and latent heat fluxes, precipitable water, cloud fraction, cloud liquid water, surface temperature, column radiative and latent heating, radiative fluxes at the top of the atmosphere and surface, etc. are also available at the same time interval. We will collect these data and form daily and monthly mean climatologies for cloud and radiation quantities. The cloud statistics obtained from our existing T42 simulations will be compared against this observed climatology. The deficiency of the current model resolution in simulation of cloud statistics of the ARM sites will be identified.

In the second stage, we will run CAM at $\mathrm{T} 85$, and compare the cloud statistics produced by the model to ARM observations. We will specifically look at daily and monthly mean cloudiness (total, low-, mid-, and high-level), cloud base height, cloud depth, and shortwave and longwave radiation fluxes at the surface and top of the atmosphere. Cloud occurrence frequency, persistence of cloudiness and covariance between cloudiness and radiative fluxes will be also analyzed for the model and compared against ARM observations. Model deficiencies and biases will be identified. The causes for the deviation of the simulated results from ARM observations will be investigated. This investigation will be carried out in addition to our conventional global and large-scale analysis.

We will then modify, with help from NCAR, the parameters related to clouds. The diagnosis of cloud fraction in NCAR AGCM represents a generalization of the scheme introduced by Slingo (1987) and cloud optical properties are accounted for using the Slingo (1989) 


\section{PROPOSAL FOR LAB 02-07: EVALUATION OF CLOUD PARAMETERIZATION}

parameterization for liquid water droplet clouds. The targeted parameters in our study are convective time scale, maximum convective cloud fraction, relative humidity threshold for cloud formation, minimum vertical velocity for low-level cloud formation, cloud base cloud liquid water, vertical cloud liquid water profile, and effective cloud drop and ice crystal radius. These parameters will be tuned so that the model results are in better agreement with observations.

In the third stage, we will build on the experience gained at T85 and investigate the cloud and radiation statistics of T239 at the ARM sites and compare against ARM datasets. At T239, the dimensions of grid cells of the model approaches the dimensions of the instrumented sections of the CART sites. Therefore, comparison of model simulated cloud statistics against ARM data becomes more meaningful and will yield valuable information regarding the ability of GCM to predict regional scale details. After the evaluation, we propose to modify the parameters in cloud and convection parameterizations for better agreement with ARM data.

\subsection{Year-by-year description of tasks}

\section{$\underline{\text { Year } 1}$}

Task 1.1: Cloud statistics and radiation measurements from ARM data for the CART sites will be collected. Meteorological and radiation measurements are available at 3-hr intervals from ARM infrastructure team at LLNL. We will specifically obtain cloud fractions in the vertical, cloud base height, cloud depth and cloud liquid water. Short and longwave radiative fluxes at the top of the atmosphere and at the surface also will be collected. Derived cloudiness information is available from Milli-Meter Cloud Radar (MMCR). The cloud fraction data will be subjected to random overlap algorithm to obtain total, low-level (surface to $700 \mathrm{mb}$ ), mid- ( $700 \mathrm{mb}$ to 400 $\mathrm{mb}$ ), and high- level (400 mb to $100 \mathrm{mb}$ ) cloudiness information. Alternatively, we will also use the cloudiness data of GOES which is also provided by the ARM data infrastructure team at LLNL. From the ARM dataset, we will form daily and monthly mean climatologies of the 


\section{PROPOSAL FOR LAB 02-07: EVALUATION OF CLOUD PARAMETERIZATION}

meteorological and radiation quantities for the columns. We will also obtain the gridded surface quantities which will be important for high-resolution model evaluation.

Task 1.2: We will compare the cloud statistics of our existing $T 42$ (the coarse resolution model) simulations at the CART sites against the cloud climatology obtained from ARM data. The deficiency in the model cloud simulation at $\mathrm{T} 42$ will be identified.

Task 1.3: We will prepare CAM for higher resolutions (T85 and T239) using our past experience with CCM3 at high-resolutions. By the time the project starts, we will most probably have experience in running CAM at T170 using SciDAC funding. Since we are interested in cloud statistics for the present day conditions, we will force the model with climatological SST and sea ice concentrations. We will prepare the appropriate initial and boundary conditions for highresolutions.

Task 1.4: Make the daily and monthly mean climatologies of cloud and radiation measurements for the ARM program CART sites publically available.

\section{$\underline{\text { Year } 2}$}

Task 2.1: We will run T85 for a few years before collecting the statistics because the land model needs to be spun up. After the initial spin up period, we will store daily and monthly means of cloudiness at all levels of the model, and total, low-level, mid- and high-level cloudiness. For the estimation of cloud occurrence frequency and persistance, we will store the cloudiness data at high frequency (3hr interval). We will also store conventional meteorological variables and radiation quantities from model simulation of present day climate.

Task 2.2: The model simulated 3 hourly, daily and monthly mean meteorological variables such as temperature, specific humidity, zonal and meridional winds, omega, precipitable water, cloudiness, cloud liquid water content, will be interpolated to levels of ARM data (every $25 \mathrm{mb}$ ).

Task 2.3: We will compare daily and monthly mean total cloudiness, cloud base height, and cloud depth simulated by the model against ARM observations for the ARM CART sites. We will also compare simulated low-, mid-, and high-level cloudiness and shortwave and longwave 


\section{PROPOSAL FOR LAB 02-07: EVALUATION OF CLOUD PARAMETERIZATION}

fluxes against the observations. We will perform cloud distribution (temporal) analysis, cloud auto-correlation analysis, and covariance analysis between cloudiness and radiation fields for ARM sites using the high frequency data ( 3 hourly). Cloud distribution or frequency analysis and cloud auto-correlation analysis will reveal the cloud occurrence frequency and persistence respectively. The correlation between radiative fluxes will be investigated for cloud-radiation feedbacks. We will investigate the reasons for the departure of the simulated cloud and radiation fields from observations by diagnosing the circulation simulated by the model at the ARM site. For instance, we will address the biases (like cold/warm and dry/wet) in the model simulation. This investigation will be performed in addition to our conventional global and large-scale analysis.

Task 2.4: In the past, we have tuned the cloud parameters in CCM3 at high resolution, with help from NCAR, to minimize the biases in global means and large-scale pattern errors in cloud and radiation fields. The parameters tuned were related to the minimum relative humidity for high level cloud formation, and evaluation of cloud liquid water content. For this project, we will collaborate with NCAR scientists to tune other parameters related to clouds and convection such as maximum convective cloud amount, convective time scale, critical vertical motion for cloud formation, relative humidity threshold for cloud formation, cloud base liquid water content, vertical profile of cloud liquid water, effective cloud drop size, effective ice particle radius, entrainment and detrainment rates, conversion rate of liquid water to rain water, CAPE consumption rate, etc. This modification of parameters will be investigated for T85. Caution will be exercised such that modification of parameters does not adversely affect the global mean and large scale features of the simulated climate.

\section{$\underline{\text { Year } 3}$}

Task 3.1: Analyze and publish results of Tasks 2.3 and 2.4 .

Task 3.2: Based on the experience gained in year 2, repeat the tasks $2.1,2.2,2.3$, and 2.4 for T239. At T239 resolution, the main limiting factor will be the demand for computer resources. 
PROPOSAL FOR LAB 02-07: EVALUATION OF CLOUD PARAMETERIZATION

CAM could be more efficient than CCM3, and computers should be faster than today as we enter into the third year of the project. Since our intention is to perform the T239 simulation for only a few years of model time, we anticipate that cost of computing resources will not be a major hurdle to the progress. Our comparison of T239 results to ARM data will provide valuable insight into the parameterization of clouds and Radiation in the AGCM because the grid cells at this resolution are quite comparable to the sections of the CART sites of ARM program.

Task 3.3: Analyze and publish results of Task 3.2.

\subsection{The Roles of Project Participants}

B. Govindasamy and P. Duffy (LLNL) have recently performed decade-long global climate simulations using the CCM3 atmospheric model at resolutions as fine as $50 \mathrm{~km}$ (T239 truncation). They have also completed shorter simulations at T340. These are the highest resolution global climate simulations to date. Their role in this project will be to

- collect the required data to perform cloud statistics from ARM program;

- perform all required simulations;

- take the lead in analyzing results;

- "tune" the CAM model at high resolution (in collaboration with NCAR).

J.J. Hack (NCAR) is the head of climate modeling section at NCAR. In this project, he will act in a primarily advisory capacity. He will

- advise LLNL on how to increase the resolution of CAM;

- help with "tuning" of CAM at high resolution;

- help with comparison of simulated cloud statistics to observations (ARM data).

R. Cederwall (LLNL) is a recognized expert on climate-related ARM data products. He is the ARM data infrastructure team leader at LLNL. In this project, he will act in a primarily advisory capacity. He will provide help in obtaining ARM data sets to form the cloud statistics. 
PROPOSAL FOR LAB 02-07: EVALUATION OF CLOUD PARAMETERIZATION

\section{Appendix: High Resolution Atmospheric Climate Simulations Performed at LLNL}

Although analysis of our T170 and T239 simulations is still in progress, the results appear very promising. Below we present some preliminary conclusions about global and annual-mean quantities, "quick-look" diagnostics, and regional detail in our high-resolution simulations of present climate. We also briefly discuss results of our T170 climate-change simulation.

Global- and annual mean quantities: Quantities relevant to the planetary radiation balance (Table Al) are within observational uncertainties, except for the net IR flux at the top of the atmosphere in the untuned (i.e. tuned for T42) T239 simulation. In the untuned T170 simulation and in the T239 simulation (also untuned) the radiation budget is out of balance in the sense that at the top of the atmosphere the outgoing IR flux exceeds the incoming solar flux. This results primarily from a deficit of mid- and high-level clouds in these simulations. This problem was eliminated by re-tuning the T170 and T239 models. Higher resolution models also produce excessive evaporation. Re-tuning also eliminates excessive evaporation and precipitation in the $\mathrm{T} 170$ and T239 models.

\begin{tabular}{|l|l|l|l|l|l|l|}
\hline Quantity & Observed & T42 & $\begin{array}{l}\text { T170 } \\
\text { untuned }\end{array}$ & $\begin{array}{l}\text { T170 } \\
\text { tuned }\end{array}$ & $\begin{array}{l}\text { T239 } \\
\text { untuned }\end{array}$ & $\begin{array}{l}\text { T239 } \\
\text { tuned }\end{array}$ \\
\hline Solar Constant & $1369 .+/-5$ & 1367. & 1367. & 1367. & 1367. & 1367. \\
\hline $\begin{array}{l}\text { Solar Down at } \\
\text { TOA }\end{array}$ & $\begin{array}{l}342.3+/- \\
1.3\end{array}$ & 341.8 & 341.8 & 341.8 & 341.8 & 341.8 \\
\hline $\begin{array}{l}\text { Planetary } \\
\text { Albedo }\end{array}$ & $\begin{array}{l}0.305+/- \\
0.013\end{array}$ & 0.307 & 0.310 & .303 & 0.306 & 0.297 \\
\hline $\begin{array}{l}\text { Net Solar at } \\
\text { Top: FSNT }\end{array}$ & $238+/-5$ & 236.9 & 235.7 & 238.33 & 237.11 & 240.40 \\
\hline $\begin{array}{l}\text { Net IR at Top: } \\
\text { FLNT }\end{array}$ & $238+/-5$ & 237.0 & 242.2 & 238.02 & 244.35 & 240.53 \\
\hline Latent H.F. & 78.0 & 89.97 & 95.29 & 91.24 & 97.6 & 92.37 \\
\hline Sensible H.F. & 24.0 & 20.47 & 19.76 & 20.76 & 19.12 & 20.32 \\
\hline
\end{tabular}

Table Al: Global- and annual-mean quantities pertaining to the planetary radiation balance.

Before tuning, the T170 and T239 models are "out of balance" in that at the top of the atmosphere there is $6.5 \mathrm{~W} / \mathrm{m}^{2}$ more outgoing (IR) than incoming (solar) energy. It is eliminated by re-tuning. 
Quantities pertaining to clouds and precipitation (Table A2) show a slight decrease in cloudiness and increase in total precipitation with increasing resolution. This increase in precipitation is the result of large increases in large-scale precipitation, and smaller decreases in convective precipitation. Changes of this type are the expected result of increasing resolution, since this results in more moist physics being explicitly calculated, and fewer being represented via parameterizations. Mid-level and high-level cloudiness decreases with increases in resolution and our re-tuning reduces this bias. Kiehl and Williamson (1991) argue that this effect is a result of increased subsidence at finer resolutions in non-convective regions. Increased subsidence is due to vigorous vertical motions in the tropical regions at higher resolutions

\begin{tabular}{|l|l|l|l|l|l|l|}
\hline Quantity & Observed & T42 & $\begin{array}{l}\text { T170 } \\
\text { untuned }\end{array}$ & $\begin{array}{l}\text { T170 } \\
\text { tuned }\end{array}$ & $\begin{array}{l}\text { T239 } \\
\text { untuned }\end{array}$ & $\begin{array}{l}\text { T239 } \\
\text { tuned }\end{array}$ \\
\hline $\begin{array}{l}\text { Cloud Fraction } \\
\text { Total }\end{array}$ & $.57+/-.05$ & .594 & .576 & .619 & .565 & .616 \\
\hline High & .14 & .346 & 0.293 & .349 & .283 & 0.341 \\
\hline Middle & .18 & .208 & 0.178 & 0.247 & 0.172 & 0.238 \\
\hline low Precip & $.26->.44$ & .348 & 0.360 & 0.3509 & 0.346 & 0.351 \\
\hline $\begin{array}{l}\text { Total } \\
\text { (mm/day) }\end{array}$ & 3.09 & 3.28 & 3.13 & 3.328 & 3.128 \\
\hline $\begin{array}{l}\text { Large-Scale } \\
\text { Precip }\end{array}$ & - & 0.480 & 0.889 & 0.840 & 1.058 & 1.000 \\
\hline $\begin{array}{l}\text { Convective } \\
\text { Precip }\end{array}$ & - & 2.61 & 2.393 & 2.29 & 2.27 & 2.128 \\
\hline
\end{tabular}

Table A2: Global- and annual-mean quantities related to clouds and precipitation. As resolution increases, the large-scale (resolved) component of precipitation increases and the convective (unresolved) component decreases.

Quick-look diagnostics: In Figures A1 and A2 we show results of two approaches to comparing the un-tuned T170 model results, the T42 model results, and observations. In both cases the T170 results were first interpolated to T42 grid; thus only the coarse-scale features of the T170 results are being evaluated. In both comparisons, the T170 model results are, in almost every aspect, closer to observations than the T42 model results are. Similarly, all but one examined quantity is 
PROPOSAL FOR LAB 02-07: EVALUATION OF CLOUD PARAMETERIZATION

simulated more realistically (in terms of spatial pattern) at T239 than T42 (Figure A3). This is true even though the results are from the un-tuned (i.e. tuned for T42) model. Tuning has little effect on the pattern errors but it helps to reduce the biases in mean quantities (Table 1).

$\underline{\text { Regional detail: }}$ Our high-resolution simulations produce beautifully detailed results. Evaluating the realism of this fine-scale detail is challenging, however, because the model resolution is finer than that of most observational data sets. In preliminary evaluations, much of the fine-scale detail in our results agrees well with available high-resolution observational data sets. Figure A4 shows an example.

Climate change simulation at T170: This simulation was performed by forcing the highresolution atmospheric model with a data set of SSTs and sea ice concentrations based on a climate change simulation performed with a coarse-resolution coupled climate model (CSM). Thus, in this simulation we essentially "downscaled" the climate predicted by CSM to finer resolution (i.e., the climate, as represented by SSTs, is predicted by CSM). For this reason, the global mean temperature change $(2100-2000)$ in this T170 simulation is very close to that in an otherwise identical simulation performed at T42. Nonetheless, there are large regions where predicted temperature changes are very different at T170 vs. T42. Figure A5 shows an example. Although we do not automatically assume that the T170 results are more nearly correct, this does cast doubt on the credibility of predictions of regional climate change performed at coarse resolution.

Preliminary conclusions: The physics parameterizations in the CCM3 model seem robust to large increases in resolution. Large increases in resolution introduce some biases into the model's present-climate results. The biases can be largely removed by re-tuning the model. The spatial patterns of nearly all of the analyzed climate fields are on the whole closer to observations at 
PROPOSAL FOR LAB 02-07: EVALUATION OF CLOUD PARAMETERIZATION

T170 than at coarse resolution. This is true even without re-tuning the model physics; re-tuning removed most of these biases and improved the spatial pattern even further. Further improvement occurs when resolution is increased from T170 to T239. Thus, we find nothing to suggest that CCM3's physics parameterizations are fundamentally unsuited to high resolution. The regional detail in our high-resolution simulations of present climate on the whole seems to agree well with observations. In our T170 climate-change simulation, global-mean climate change results are very similar to those in comparable $\mathrm{T} 42$ simulations, but regional climate change results can be very different. 


\section{Figures}

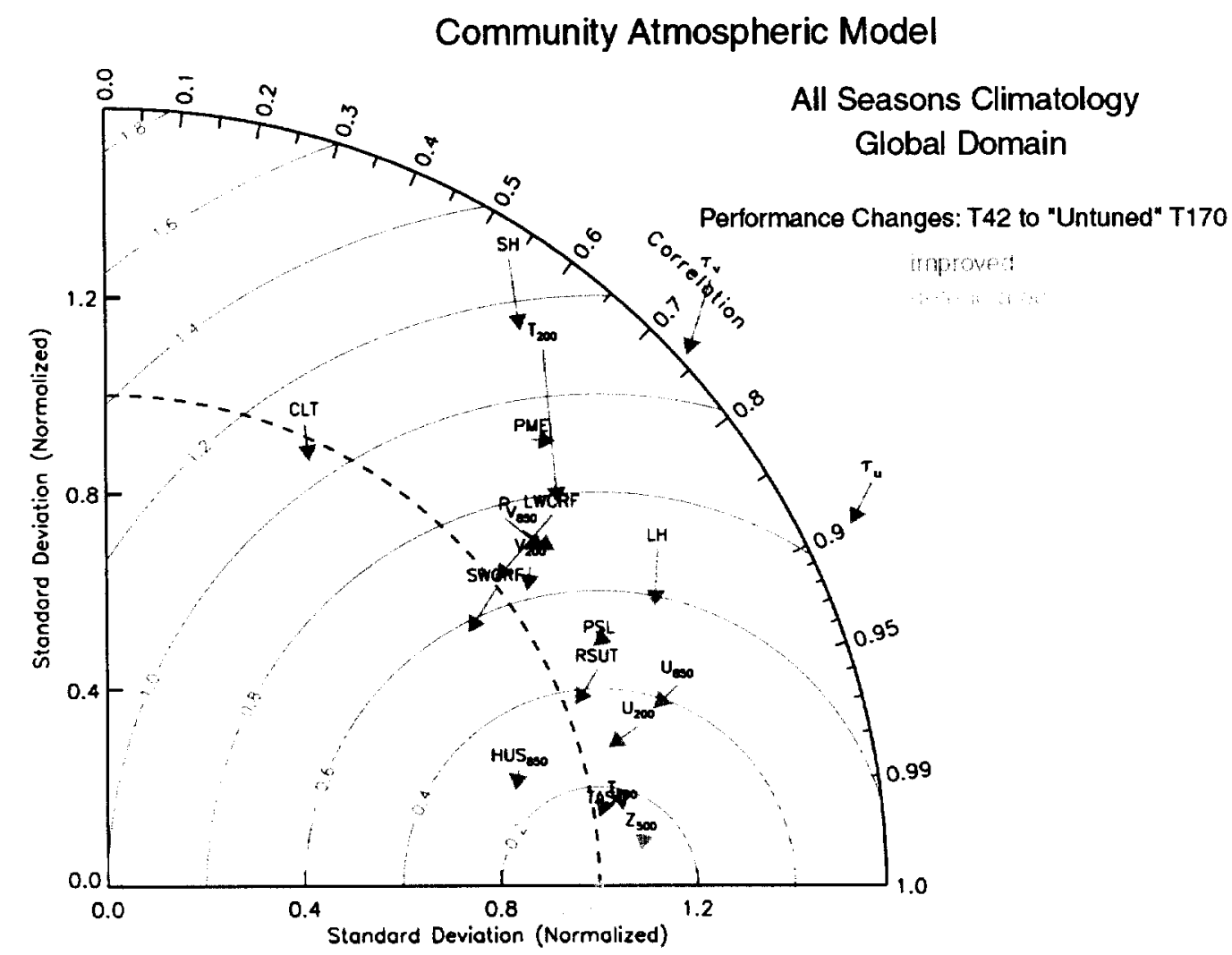

Figure A1: "Taylor diagram" comparing results of un-tuned T170 model, T42 model, and observations. For this comparison, the T170 results are first interpolated to the T42 grid. Thus, this comparison evaluates only coarse-scale features in the $\mathrm{T} 170$ results. The radial coordinate is the spatial standard deviation of the model results, normalized by the standard deviation of observations. The angular coordinate is the correlation between the patterns of model results and observations. A perfect model would be represented by radial and angular coordinate values of $(1,1)$. Each arrow represents model results for one climatic quantity. The tail of the arrow shows the performance of the model at T42; the head represents the results of the T170 model. For 18 quantities, the T170 results are closer to observations than the T42 results (blue arrows). For 1 quantity (red arrow) the T42 results are better. Thus, even in the untuned T170 model, large-scale results are much more realistic at $\mathrm{T} 170$ than $\mathrm{T} 42$. 
T170CLIM: Absolute Difference from CCM3.5.27

PCMDI Normalized Bias
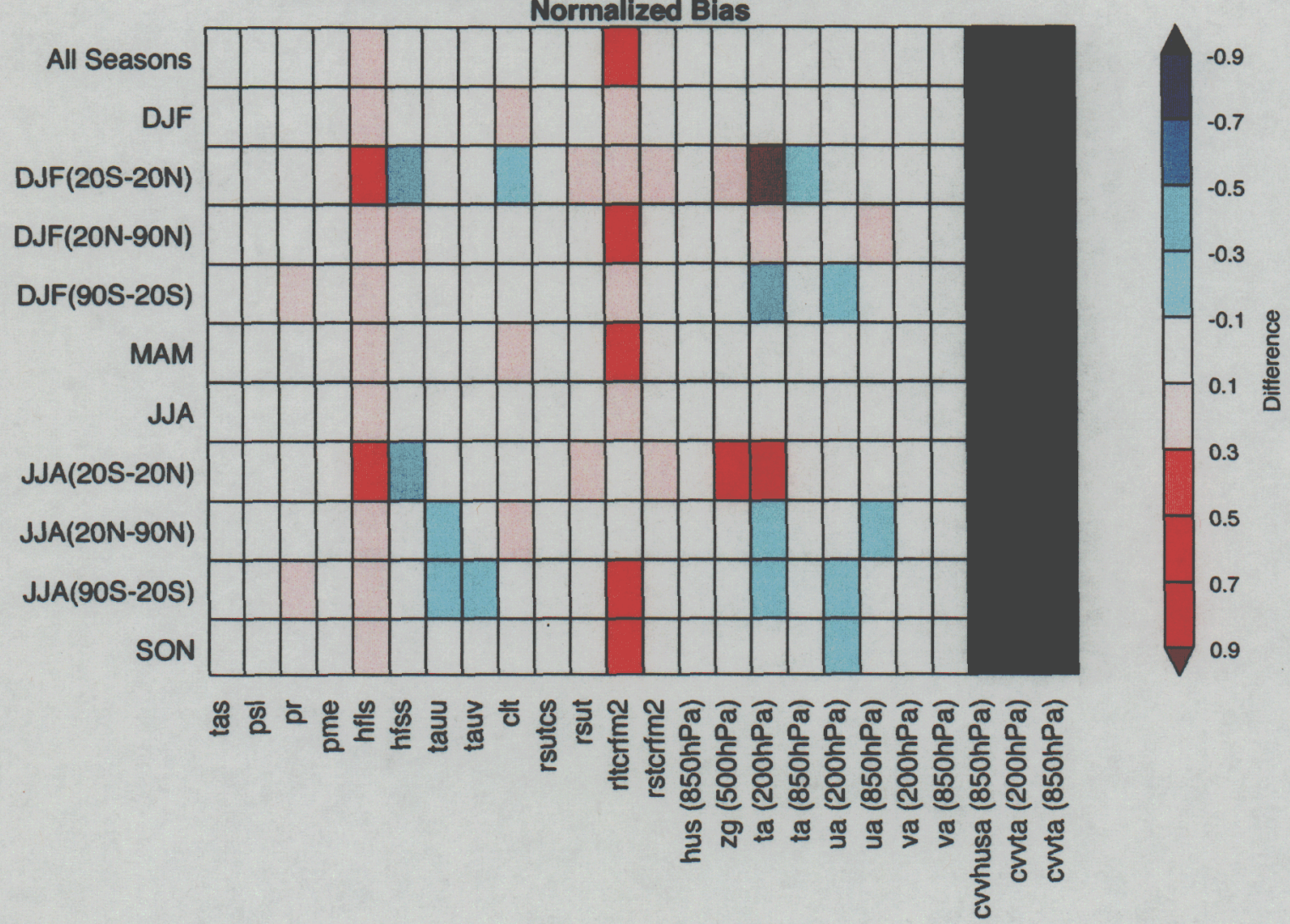

Figure A2: "Portrait diagram" comparing the biases (deviation of mean quantities from observations) of un-tuned T170 model, and T42 model. The model and observed data are mapped to $2.5^{\circ} \times 2.5^{\circ}$ latitude-longitude grid before computing the statistics. For many quantities analyzed, the bias in the un-tuned T170 model results not significantly different from that in the T42 model (white squares). In many other cases the T170 error is less than that in the T42 results (blue squares). One region where this is not true is between latitudes $20 \mathrm{~N}$ and $90 \mathrm{~N}$ (some red squares); this likely results from errors in longwave cloud radiative forcing in this region. Biases have increased in $\mathrm{T} 170$ for out going longwave radiation (hfls) and longwave cloud radiative forcing (rltcrfm2). The global mean biases are reduced in the tuned T170 model (Table 1 and 2). 


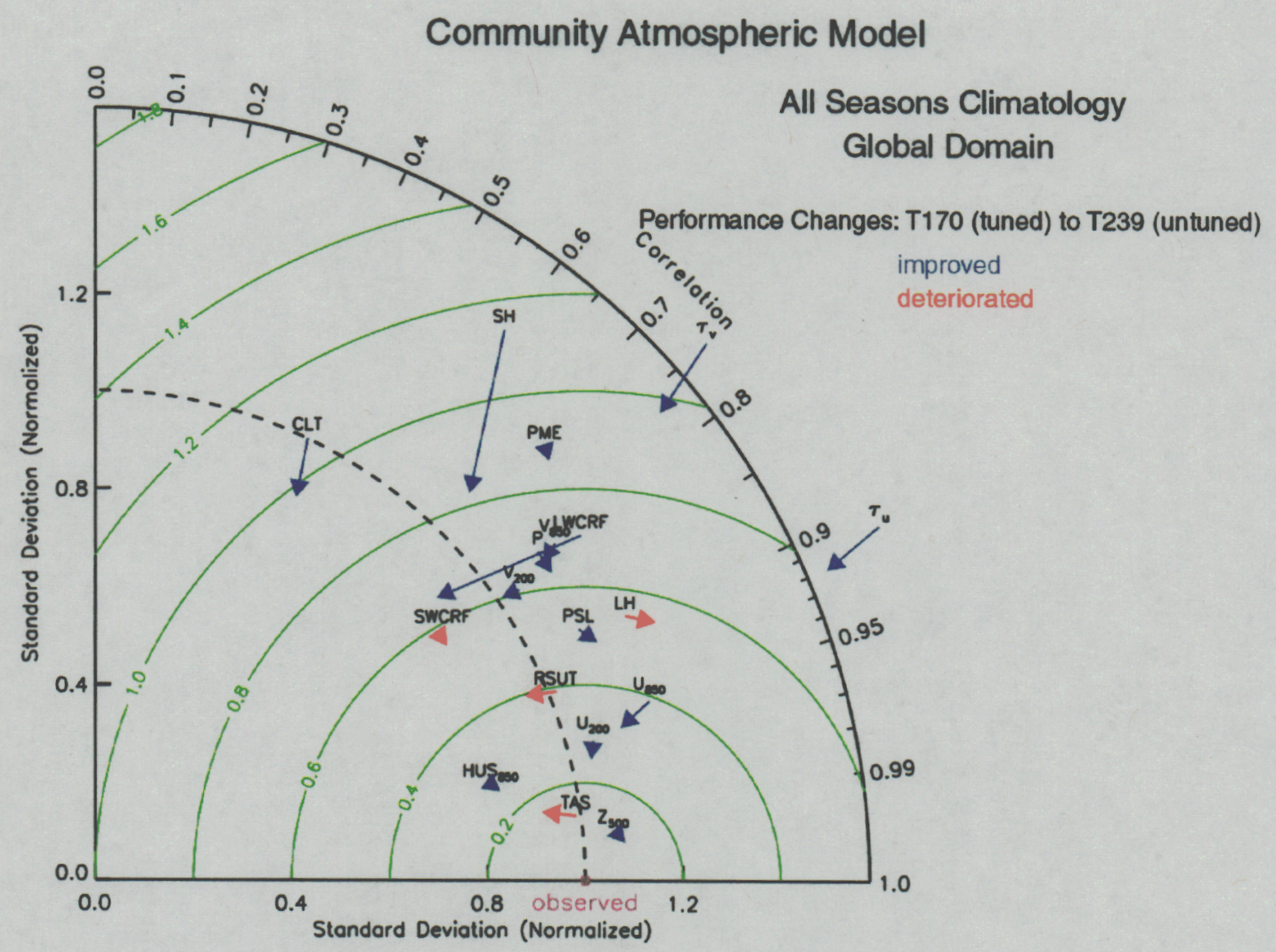

Figure A3: Same as Figure A1, except results being compared are tuned T170 simulation and untuned T239 simulation. Results are for all seasons, global domain. All but four examined quantities is simulated more realistically (in terms of spatial pattern) at T239 than T170. Therefore, increasing the resolution from T170 to T239 shows further improvement in spatial patterns of many simulated quantities. 


\section{CCM3@T42}

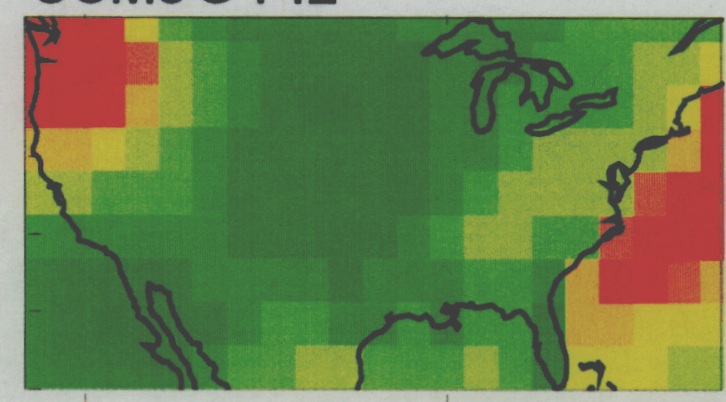

CCM3@T170
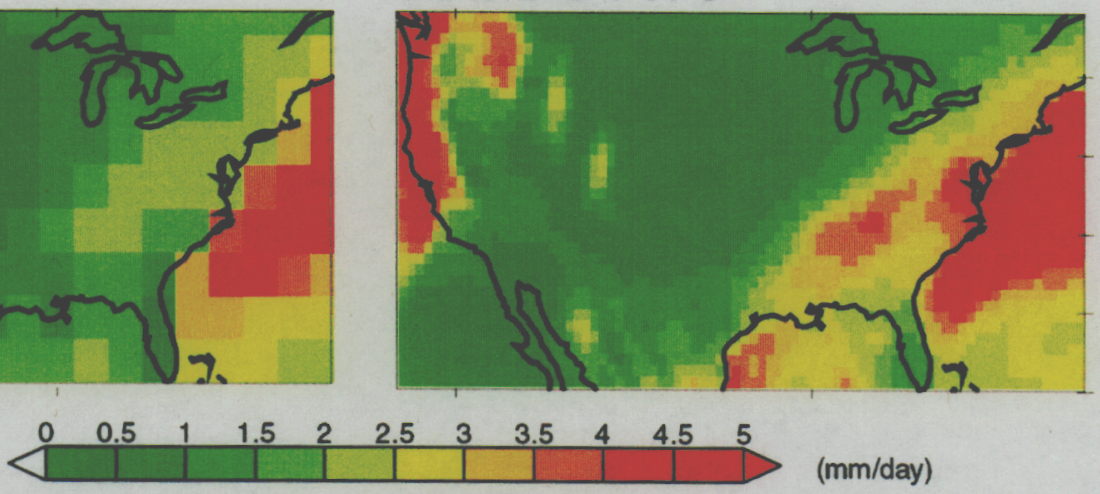

CCM3@T239

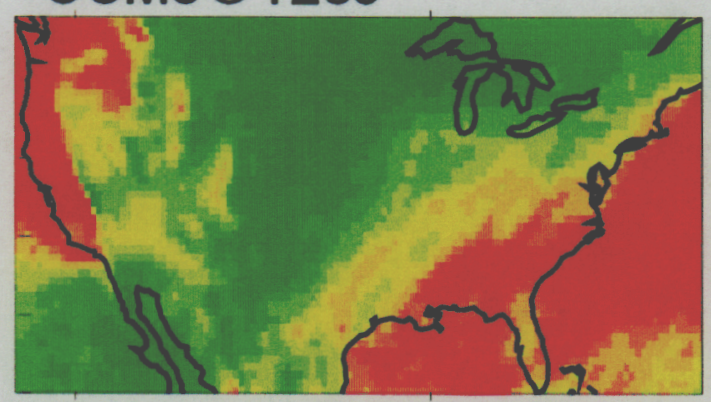

VEMAP observations

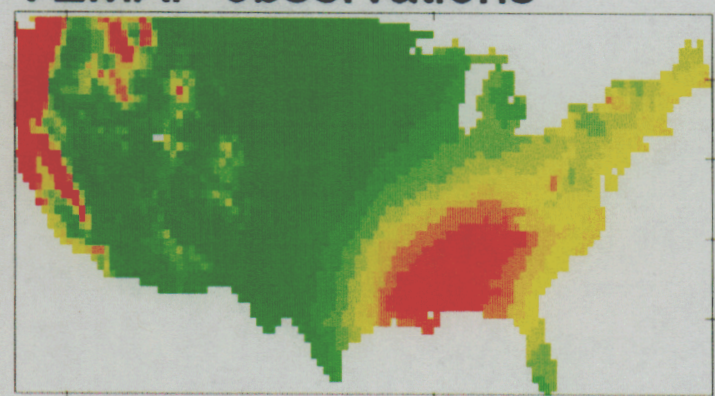

Figure A4: Wintertime precipitation over the USA in the T42 model, un-tuned T170 model, T239 model, and in the VEMAP observational data set. In the higher resolution simulations, observed regional precipitation features in the western U.S. and the precipitation maximum in the southeastern U.S. are represented. 


\section{Predicted DJF Temperature Change, 2100 - 2000}
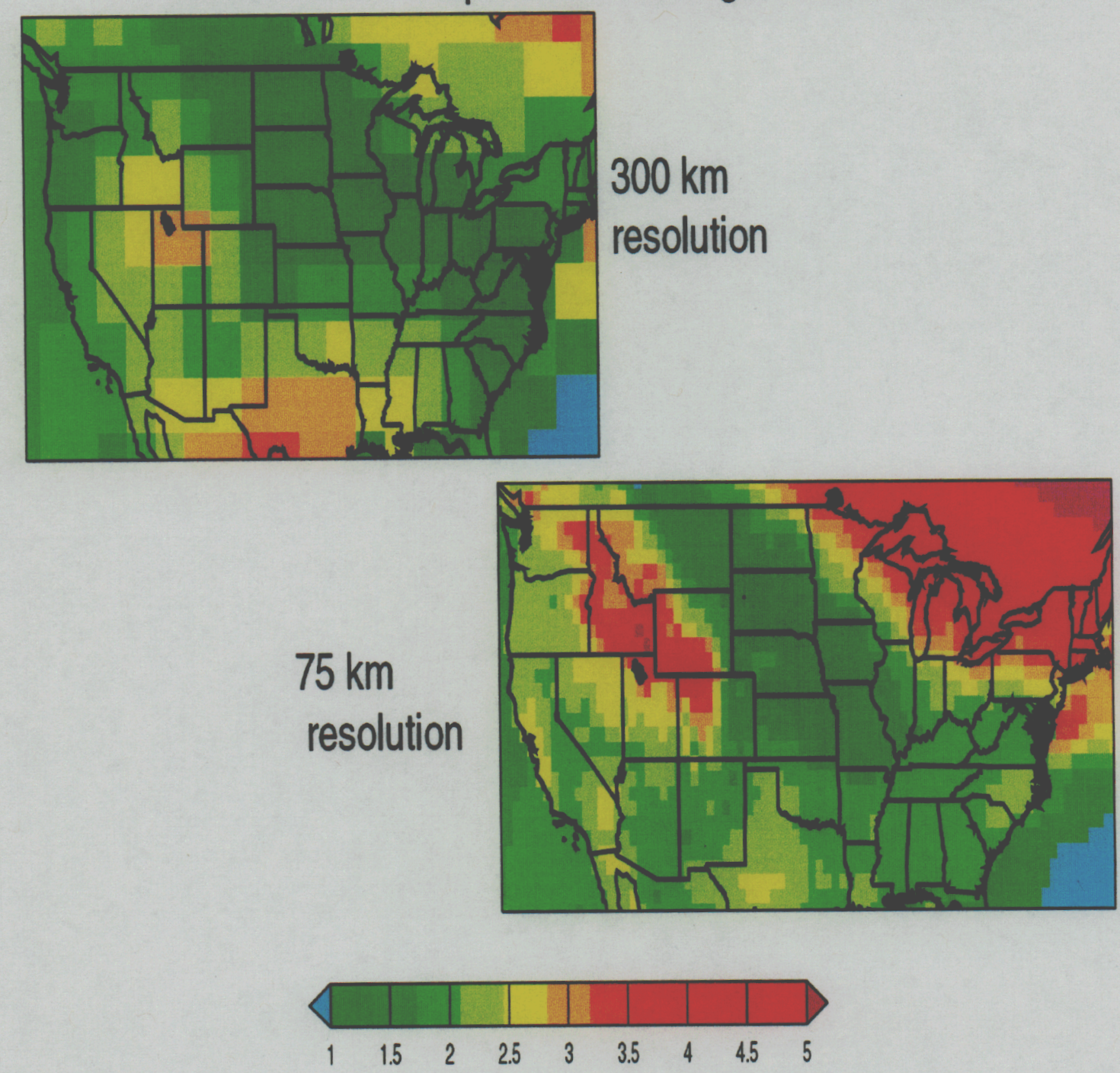

Figure A5: Predicted changes in reference height temperature (2100 minus 2000) in Kelvin from the CCM3 model (forced with prescribed SSTs and sea ice concentrations) at T170 truncation (right) and T42 (left). Although the general patterns of predicted temperature change is similar, and although global mean temperature changes are similar, in many regions in North America the $\mathrm{T} 170$ model predicts more temperature change than the T42 model does. 


\section{References}

Betts, A. K., and M. J. Miller, A new convective adjustment scheme. Part II: Single column tests using GATE wave, BOMEX, ATEX, and arctic air-mass data sets, Quart. J. Roy. Meteor. Soc., 112, 693-709, 1986.

Boer, G.J., and M. Lazare, Some results concerning the effect of horizontal resolution and gravity wave drag on simulated climate, J. Climate, 1, 789-806, 1988.

Boer, G. J., and B. Denis, Numerical convergence of the dynamics of a GCM, Climate Dyn., 13, 359-374, 1997.

Boville, B., Sensitivity of simulated climate to model resolution, J. Climate, 4, 469-485, 1991.

Boyle, J., Sensitivity of dynamical quantities to horizontal resolution for a climate simulation using the ECMWF (cycle 33) model, J. Climate, 6, 796-815, 1993.

Cederwall, R. T., S. K. Kruger, S. Xie, and J. Yio, 2000: ARM/GCSS Single Column Model (SCM) intercomparison, Procedures for Case 3: Summer 1997 SCM IOP, LLNL Report, UCRL-ID-141823, 20pp.

Cess, R., G. L. Potter, et al., Intercomparison of cloud-climate feedback as produced by 14 atmospheric general circulation models, Science, 24, 513-516, 1989.

Duffy, P. B., B. Govindasamy, J. Milovich, J. J. Hack, K. Taylor, M. Wehner, and S. Thompson, 2002: High Resolution Simulations of Global Climate Using the CCM3 Atmospheric General Circulation Model (manuscript under preparation)

Ghan, S. J., et al., 2000: An intercomparison of single column model simulations of summertime midlatitude continental convection, J. Geophys. Res., 105, 2091-2124.

Gleckler, P.J. and K.E. Taylor, The effect of horizontal resolution on ocean surface heat fluxes in the ECMWF model, Climate Dynamics, 9, 17-32, 1993.

Govindasamy, B., P. B. Duffy, S. L. Thompson, J. Milovich, 2002: High-resolution global simulation of the climatic effects of increased greenhouse gases (manuscript under preparation)

Grell, G. A., Y.-H. Kuo, and R. Pasch, Semi-prognostic tests of cumulus parameterization schemes in the middle latitudes, Mon. Wea. Rev., 119, 5-31, 1991.

Kao, C.-Y.J., and Y. Ogura, Response of cumulus clouds to large-scale forcing using ArakawaSchubert cumulus parameterization, J. Atmos. Sci., 44, 2437-2458, 1987.

Kiehl, J.T., and Williamson, D.L., Dependence of cloud amount on horizontal resolution in the national center for atmospheric research community climate model, J. Geophys Res., 96, $10,55-10,980,1991$. 
Lord, S. J., Interaction of a cumulus cloud ensemble with the large scale environment. Part III: Semi-prognostic test of the Arakawa-Schubert cumulus parameterization, J. Atmos. Sci., 39, 88-103, 1982.

Manabe, S., J. Smagorinsky, J.L. Holloway, and H.M. Stone, Simulated climatology of a general circulation model with a hydrological cycle, Mon. Wea. Rev., 98, 175-213, 1970.

Phillips, T.J., L.C. Corsetti, and S.L. Grotch, The impact of horizontal resolution on moist processes in the ECMWF model, Climate Dynamics, 11, 85-102, 1995.

Randall, D. A., K-M. Xu, R. J. C. Sommerville, and S. Jacobellis, 1996: Single column models and cloud ensemble models as links between observations and climate models, J. Climate, 9 , 1683-1697.

Rind, D. Dependence of warm and cold climate depiction on climate model resolution, $J$. Climate, 1, 965-997, 1988.

Slingo, J. M., The development and verification of a cloud prediction scheme for the ECMWF model, Quart. J. Roy. Meteor. Soc., 113, 899-927, 1987.

Slingo, A., A GCM parameterization for the shortwave radiative properties of water clouds, $J$. Atmos. Sci., 46, 1419-1427, 1989.

Sperber, K. R., S. Hameed, G. L. Potter, J. S. Boyle, Simulation of the northern summer monsoon in the ECMWF model: sensitivity to horizontal resolution, Mon. Wea. Rev., 122, 2461-2481, 1994.

Tibaldi, T., N. Palmer, C. Brankovic, and U. Cabasch, Extended-range predictions with ECMWF models: influence of horizontal resolution on systematic error and forecast skill, Q.J.R. Meteorol. Soc., 115, 835-866, 1990.

Wellck, R.E., A. Kasahara, W.M. Washington, and G. de Santo, Effect of horizontal resolution in a finite difference model of the general circulation, Mon. Wea. Rev., 99, 673-683, 1971.

Williamson, D. L., J. T. Keihl, J. J. Hack, Climate sensitivity of the NCAR Community Climate Model (CCM2) to horizontal resolution, Climate Dyn., 11, 377-397, 1995.

Williamson, D. L., Convergence of atmospheric simulations with increasing horizontal resolution and fixed forcing scales, Tellus, 51A, 663-673, 1999. 
PROPOSAL FOR LAB 02-07: EVALUATION OF CLOUD PARAMETERIZATION

BUDGET AND BUDGET JUSTIFICATION 


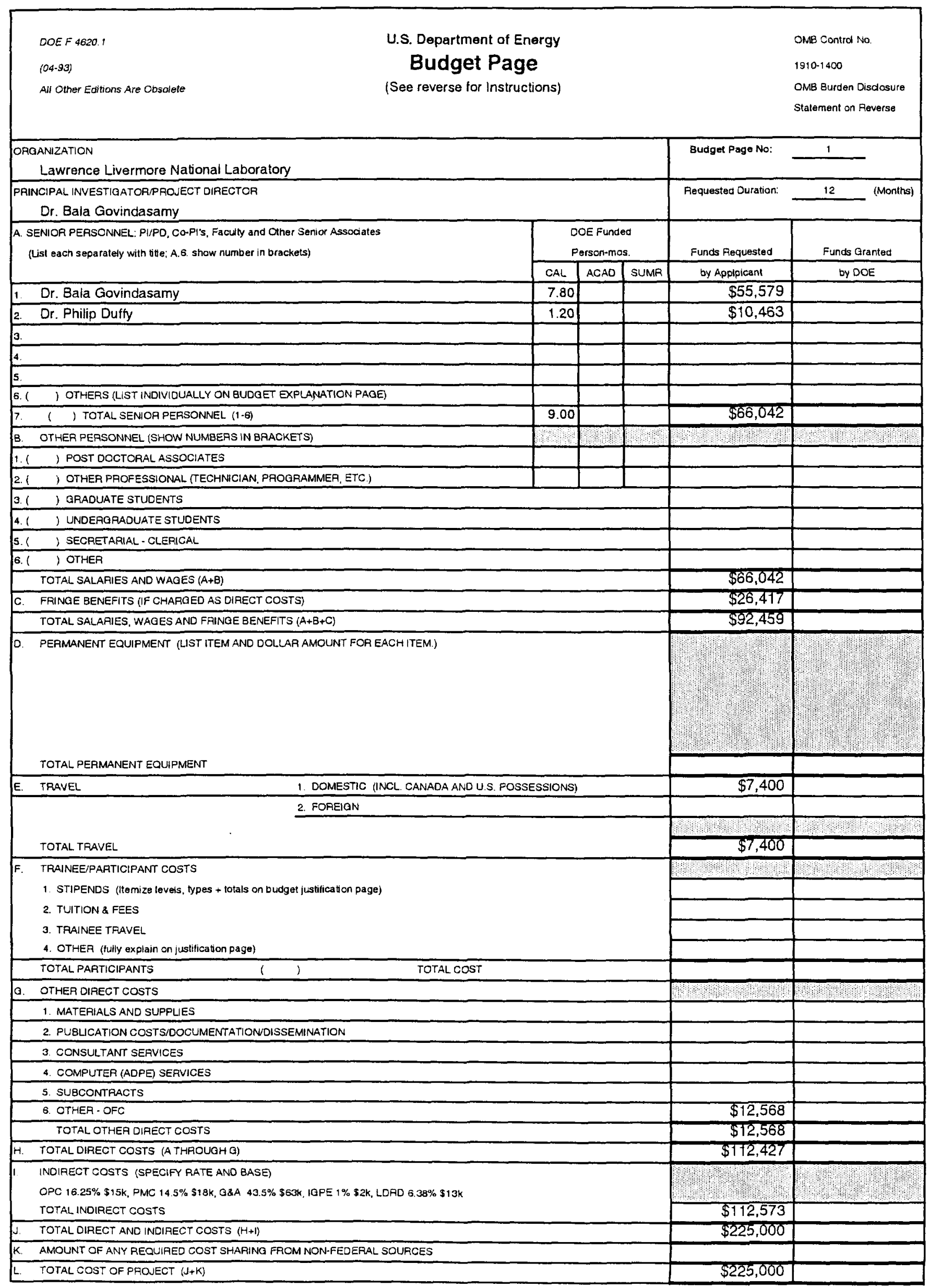




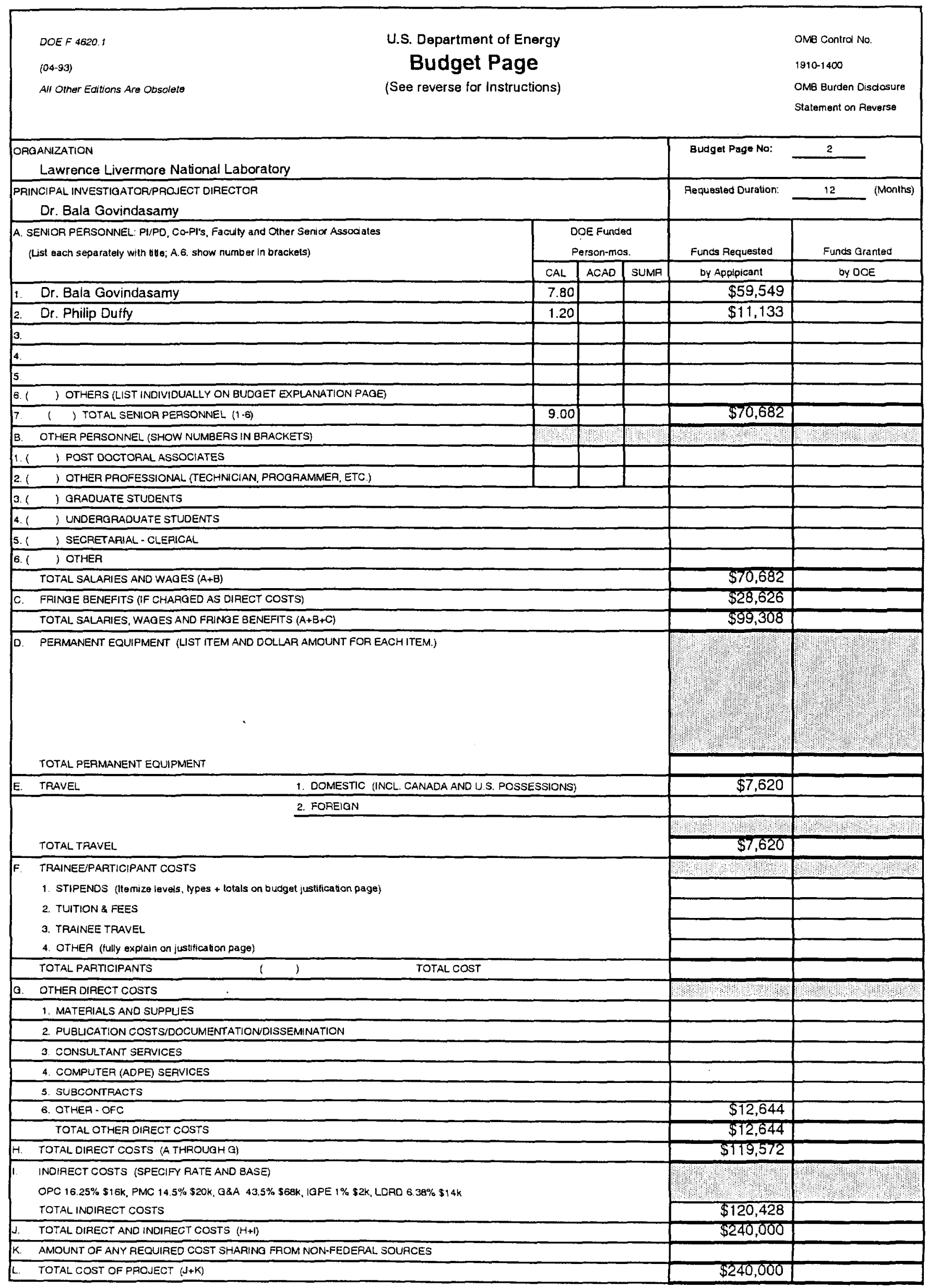




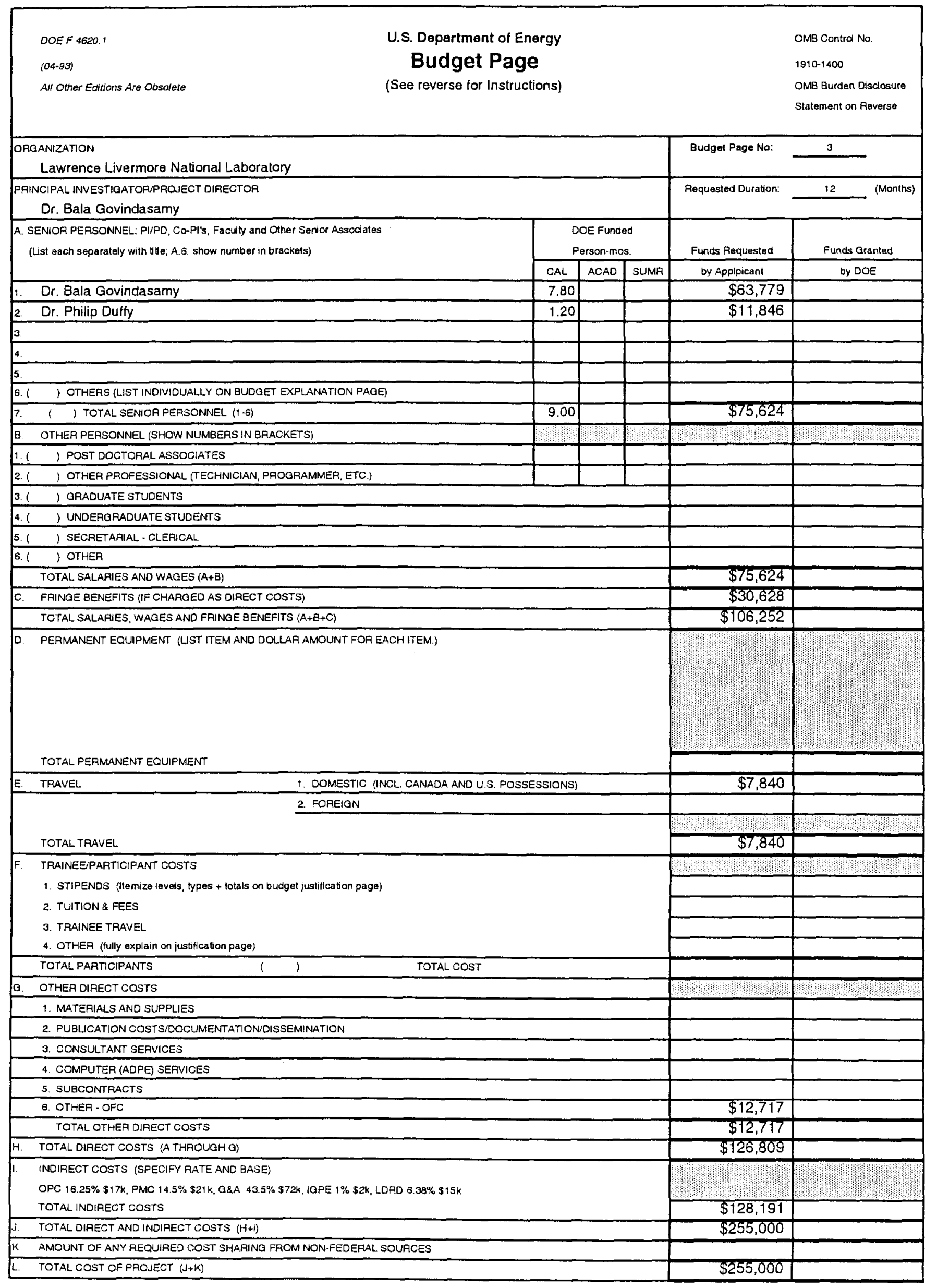




\section{LLNL INDIRECT COST SUMMARY}

Rates used for this proposal are forward pricing rates approved by Department of Energy (DOE)

Note 1: $\quad$ General \& Administrative G\&A

This rate is distributed over a value added base. The value added base is determined by using total costs of the project less procurements, postdoctoral and students G\&A, HWC, IGPE and LDRD. The rate for FY2002 is $43.5 \%$. The same rate is used for out years.

Note 2: $\quad$ Laboratory Directed Research \& Development (LDRD)

The policy of LLNL and the DOE to foster the creation of new science and technology, to advance the forefront of science, and to find novel, high-leverage innovative approaches to scientific and technological problems in fields related to LLNL's defense and energy missions. To accomplish this, the LDRD program was established and is currently funded by a $6 \%$ assessment on all LLNL operating costs. The rate is $6.38 \%$ of total costs. The same rate is used for out years.

Note 3: $\quad$ Organizational Personnel Charge (OPC)

This charge is calculated as a percentage of wage expense (salary plus fringe benefits). This rate is to recover indirect personnel management costs by each directorate. The FY2002 estimated rate for energy and Environment personnel is $16.25 \%$. The same rate is used for out years.

Note 4: $\quad$ Program Management Charge (PMC)

This charge is calculated on a percentage of the same value added base as G\&A. This rate is to recover the indirect program management costs. The FY2002 estimated rate is $14.5 \%$. The same rate is used for out years.

Note 5: $\quad$ Organizational Facility Charge (OFC)

OFC is distributed by FTE percentage * 16,800. The 16,800 was calculated based on the number of FTE's and total square feel and total costs of facilities, including office's and labs which gives an average square feet per FTE of 486.

Note 6: $\quad$ Institutional General Purpose Equipment (IGPE)

The IGPE supports strategic Laboratory objective(s), which transcends multiple programs. Cost of an IGPE item cannot equitably and cost effectively be allocated to one program. The rate will be $1.0 \%$ of its distribution base.

Note 7: $\quad$ Material Procurement Charge (MPC)

Material ordering and handling charge. The individual rate is based on the procedure used in ordering item(s). 
Budget Justification
A1: Bala Govindasamy, Principal Investigator, 7.8 months
A2: Phil Duffy, Co-Investigator, 1.2 months
C: $\quad$ Fringe Benefit - FY03 40\%, FY04 40\%, FY05 41\%
E: $\quad$ Travel - Domestic: 1 person, 2 trips of 1 week each to Washingtion DC and 2 trips of 3 days each to Chicago, Illinois from Livermore, California to attend ARM Science Team meetings and subcommittee meetings.

G1: Organizational Facility Charge (OFC): To distribute the operations and maintenance costs of individual facilities

Drs. J. Hack, and R. Cederwall will act in a primarily advisory capacity. We are not requesting any funds to support them. 
PROPOSAL FOR LAB 02-07: EVALUATION OF CLOUD PARAMETERIZATION

OTHER SUPPORT OF INVESTIGATORS 


\section{Current and Pending Support}

(See GPG Section II.D.8 for quidance on information to include on this form.) The following information should be provided for each investigator and other senior personnel. Failure to provide this information may delay consideration of this proposal.

\begin{tabular}{|l|l|l|}
\hline Investigator: Philip Duffy & Other agencies (including NSF) to which this proposal has been/will \\
\hline Support: $\quad$ Current $\square$ Pending $\square$ Submission Planned in Near Future $\square *$ Transfer of \\
\end{tabular}

Project/Proposal Title:

High Resolution Climate Modeling

Source of Support: DOE

Total Award Amount: \$150K

Total Award Period Covered: 10.1.01-9.30.02

Location of Project: LLNL

Person-Months Per Year Committed to the Project.

6

Cai: 6

Acad:

Sumr:

Support: $\square$ Current $\times$ Pending $\square$ Submission Planned in Near Future $\square_{\text {Support }}^{*}$ Transfer of

Project/Proposal Title: Simulations of Effects of Anthropogenic Climate Change on Arctic Sea Ice using a Model including a high resolution AGCM

Source of Support: NASA

Total Award Amount: $\$ 930 \mathrm{~K}$

Total Award Period Covered:

Location of Project: LLNL

Person-Months Per Year Committed to the Project.

Cal: 3

Acad: 3

Sumr:

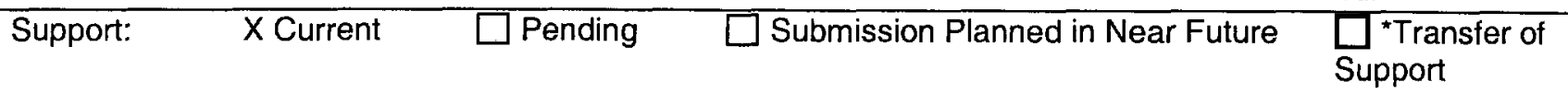

Project/Proposal Title:

Source of Support: DOE (SiDAC)

Total Award Amount: \$20M

Total Award Period Covered: 10.1.01-9.30.06

Location of Project: LLNL and elsewhere

Person-Months Per Year Committed to the Project.

Cal: 3

Acad: 3

Sumr:

Support: $\square$ Current $\square$ Pending X Submission Planned in Near Future

Support

Project/Proposal Title: Evaluation of cloud parameterizations in a high resolution atmospheric general circulation model using ARM data (This proposal)

Source of Support: DOE

Total Award Amount: $\$ 720 \mathrm{~K}$ Total Award Period Covered:

Location of Project: LLNL

Person-Months Per Year Committed to the Project. Cal: Acad: Sumr:

*If this project has previously been funded by another agency, please list and furnish information for immediately preceding funding period.

NSF Form 1239 (10/99)

\section{Current and Pending Support}




\section{PROPOSAL FOR LAB 02-07: EVALUATION OF CLOUD PARAMETERIZATION}

(See GPG Section II.D.8 for quidance on information to include on this form.) The following information should be provided for each investigator and other senior personnel. Failure to provide this information may delay consideration of this proposal.

\begin{tabular}{|l|ll|}
\hline Investigator: Bala Govindasamy & Other agencies (including NSF) to which this proposal has been/will \\
\hline Support: $\quad$ QCurrent $\square$ Pending $\square$ Submission Planned in Near Future $\square_{\text {Support }}^{*}$ Transfer of
\end{tabular}

Project/Proposal Title:

High Resolution Climate Modeling

Source of Support: DOE

Total Award Amount: \$150K

Total Award Period Covered: 10.1.01-9.30.02

Location of Project: LLNL

Person-Months Per Year Committed to the Project. 3 Cal: 3 Acad: Sumr:

Support: $\square$ Current $\times$ Pending $\square$ Submission Planned in Near Future $\square$ Support

Project/Proposal Title: Simulations of Effects of Anthropogenic Climate Change on Arctic Sea Ice Using a Model Including a High Resolution AGCM

Source of Support: NASA

Total Award Amount: \$930K

Total Award Period Covered:

Location of Project: LLNL

Person-Months Per Year Committed to the Project.

Cal: 3

Acad: 3

Sumr:

Support: X Current $\square$ Pending $\square$ Submission Planned in Near Future $\square_{\text {Support }}^{\star *}$ Transfer of

Project/Proposal Title:Integrated Climate and Carbon (INCCA)

Source of Support: LLNL Laboratory-Directed Research and Development

Total Award Amount: $\$ 2700 \mathrm{~K} \quad$ Total Award Period Covered: 10.1.00-9.30.03

Location of Project: LLNL

Person-Months Per Year Committed to the Project.

Support: $\square$ Current $\square$ Pending X Submission Planned in Near Future

Sumr:

Support
Project/Proposal Title: Evaluation of cloud parameterizations in a high resolution atmospheric general circulation model

using ARM data (This proposal)

Source of Support: DOE

Total Award Amount: $\$ 720 \mathrm{~K}$

Total Award Period Covered:

Location of Project: LLNL

Person-Months Per Year Committed to the Project.

Cal: 3

Acad: 3

Sumr:

*If this project has previously been funded by another agency, please list and furnish information for immediately preceding funding period.

NSF Form 1239 (10/99) 
PROPOSAL FOR LAB 02-07: EVALUATION OF CLOUD PARAMETERIZATION

\section{BIOGRAPHICAL SKETCHES}

Bala Govindasamy

Phil Duffy 


\section{Curriculum Vitae}

\section{Balasubramanian Govindasamy}

\section{PRESENT POSITION}

Physicist

Climate and Carbon Cycle Modeling Group

Lawrence Livermore National Laboratory

Atmospheric Science Division

Livermore, CA 94550

Ph: 925-423-0771

Fax: 925-422-6388

Email: bala@LLNL.GOV

PERSONAL:

Citizenship: India

\section{HONORS \& MEMBERSHIPS:}

McGill-CIDA (Canadian International Development Agency) Fellowship, 1990-1994. TIFR Scholarship, 1986-1988.

Government of India Merit Scholarship, 1981-1986.

Merit Scholarship, 1979-1981.

American Geophysical Union

\section{EDUCATION:}

Ph.D., 1994, McGill University, Canada (Atmospheric and Oceanic Sciences)

M.Sc, 1988, University of Poona, India (Physics)

B.Sc, 1986, University of Madras, India (Physics)

\section{PREVIOUS RESEARCH EXPERIENCE:}

1994 - 1996: Visiting Research Staff, Princeton University, Princeton, NJ

1996 - 1998: Staff Research Associate, UCLA, Los Angeles, CA

\section{RESEARCH INTERESTS:}

Atmospheric General Circulation Modeling (AGCM), coupled Ocean-Atmosphere-Land system modeling, regional and global climate change studies, and High Performance computing.

\section{PRINCIPAL PUBLICATIONS}

Govindasamy, B., K. Caldeira, and P. B.Duffy, 2001: Geoengineering Earth's radiation balance to mitigate climate change from a quadrupling of $\mathrm{CO}_{2}$ (accepted for publication in Global and Planetary Change). 
Govindasamy, B., A. Grossman, K.E.Grant, and P.B.Duffy, 2001: Global warming potentials modified for differences in climate sensitivity (submitted to $J$. Geophys. Res.)

B. Govindasamy, K. E. Taylor, P. B. Duffy, B. J. Santer, A. S. Grossman, and K. E. Grant, 2001: Limitations of the equivalent $\mathrm{CO}_{2}$ approximation in climate change simulations, J. Geophys. Res., 106, 22593-22603.

Bala Govindasamy, Phil Duffy, and Ken Caldeira, 2001: Land use change and Northern Hemisphere cooling, Geophys. Res. Lett., 28 , No. 2, p. 291.

Bala Govindasamy and Ken Caldeira, 2000: Geoengineering earth's radiation balance to mitigate CO2-induced climate change, Geophys. Res. Lett., 27 , No. 14 , p. 2141

Teller, E., K. Caldeira, G. Canavan, B. Govindasamy, A. Grossman, R. Hyde, M.Ishikawa, A. Ledebuhr, C. Leith, C. Molenkamp, J. Nuckolls, and L. Wood, 1999: Long-range weather prediction and prevention of climate catastrophes: A status report. $24^{\text {th }}$ International Seminar on Planetary Emergencies, Erice, Italy, 19-24 August 1999.

B.Govindasamy, M.F.Wehner, C.R.Mechoso, and P.B.Duffy, 1999: The influence of a SoilVegetation-Atmosphere Transfer scheme on the simulated climate of LLNL/UCLA AGCM. Global and Planetary Change, 20, 67-86.

B.Govindasamy, and S.T.Garner, 1997: The equilibration of short baroclinic waves. J. Atmos Sci., 54, 2850-2871.

G.Balasubramanian, and S.T.Garner, 1997: The role of eddy momentum fluxes in shaping the lifecycle of a Baroclinic wave. J. Atmos. Sci., 54, 510-533.

G.Balasubramanian, and S.T.Garner, 1996: The role of eddy momentum fluxes in shaping the lifecycle of a Baroclinic wave. Joint AMS-RMS $7^{\text {th }}$ conference on mesoscale processes, Reading, United Kingdom.

G.Balasubramanian, and M.K.Yau, 1996: The lifecycle of a simulated marine cyclone: Energetics and PV Diagnostics. J. Atmos. Sci., 53, 639-563.

G.Balasubramanian, and M.K.Yau, 1995: Explosive marine cyclogenesis in a three layer model with a representation of slantwise convection: A sensitivity study. J. Atmos. Sci., 52, 533-550.

G.Balasubramanian, and M.K.Yau, 1994a: Baroclinic instability in a two-layer model with parameterized slantwise convection. J. Atmos. Sci., 51, 674-701.

G.Balasubramanian, and M.K.Yau, 1994b: Effects of convection on a simulated marine cyclone. J. Atmos. Sci., 51, 2397-2417.

G.Balasubramanian, and M.K.Yau, 1994c: An evaluation of the interaction between slantwise convection and marine cyclogenesis. Preprint volume of Cyclone symposium, Bergen, Norway.

G.Balasubramanian, and M.K.Yau, 1994d: Interaction between slantwise convection and marine cyclogenesis: A conceptual picture and sensitivity studies. Sixth conference on mesoscale processes, Portland, Oregon. 


\section{Philip B. Duffy}

Group Leader, Climate and Carbon Cycle Modeling Group

Atmospheric Science Division, LLNL

\section{Address}

Lawrence Livermore National Lab.

University of California

P.O. Box 808, L-103

Livermore, CA 94550
Telephone: (925) 422-3722

Fax: (925) 422-6388

email: pduffy@llnl.gov

http://en-env.llnl.gov/cccm/

\section{Education}

A.B., Magna Cum Laude, Astronomy and Astrophysics, Harvard University.

M.S., Applied Physics (Astrophysics), Stanford University, Palo Alto, Ca.

Ph.D., Applied Physics (Astrophysics), Stanford University, Palo Alto, Ca.

\section{Employment}

Sept., 1993-Present:

Atmospheric Science Division, Lawrence Livermore National Laboratory (LLNL)

April 1989-Sept., 1993:

Computational Physics Group, Nuclear Test Division, LLNL

July 1986-April 1989:

Strategic Defensive System Studies Group, LLNL

\section{Research Interests}

Global climate change; climate modeling; detection of anthropogenic climate change, societal impacts of climate change.

\section{Honors}

Magna Cum Laude, Harvard University 1979

Co-captain, Stanford Cycling Team 1982-83

NASA Graduate Student Fellowship 1982-1986

\section{Refereed Publications}

M.E. Wickett, K. Caldeira, and P.B. Duffy, High-resolution simulations of direct-injection of anthropogenic $\mathrm{CO}_{2}$ and $\mathrm{CFC}$ uptake, submitted to J. Geophys. Res.

J. L. Bell, L. Sloan, P. B. Duffy, Evaluation of Northern Hemisphere natural climate Variability in multiple temperature reconstructions and global climate model simulations, to be submitted to Climate Dynamics.

M. A. Snyder, Jason L. Bell, Lisa C. Sloan, Philip B. Duffy, Climate responses to a doubling of atmospheric carbon dioxide since the preindustrial era for a climatically vulnerable region, submitted to Geophysical Research Letters.

P. B. Duffy, C. Doutriaux, I. Fodor, and B. Santer, Effect of Missing Data on Estimates of NearSurface Temperature Change Since 1900, J. Climate, 14, 2809-2814, 2001.

P. B. Duffy, M.E. Wickett, and K. Caldeira, Effect of horizontal grid resolution on the nearequilibrium solution of a global ocean/sea ice model, J. Geophys. Res, in press. 
B. Govindasamy, K. E. Taylor, P. B. Duffy, B. J. Santer, A. S. Grossman, and K. E. Grant, Limitations of the equivalent $\mathrm{CO}_{2}$ approximation in climate change simulations; J. Geophys. Res., 106, p. 22593-22603, 2001.

Weaver, A.J., M. Eby, E. C. Wiebe, C. M. Bitz, P. B. Duffy, T. L. Ewen, A. F. Fanning, M. M. Holland, A. MacFadyen, H. D. Matthews, K. J. Meissner, O. Saenko, A. Schmittner, H. Wang and M. Yoshimori, 2001: The UVic Earth System Climate Model: Model description, climatology and application to past, present and future climates. Atmosphere-Ocean, in press.

B.J. McAvaney et al, "Model Evaluation”, in Climate Change: The Scientific Basis; IPCC Third Assessment Report, Cambridge University Press, 2001.

P. B. Duffy, M. Eby, and A.J. Weaver, Climate Model Simulations of Effects of Increased Atmospheric $\mathrm{CO}_{2}$ and Loss of Sea Ice on Ocean Salinity and Tracer Uptake, J. Climate, 14, 520-532, 2001.

B. Govindasamy, P. B. Duffy, and K. Caldeira, Land Use Changes and Northern Hemisphere Cooling, Geophys. Res. Lett, 28, 291-294, 2001.

M. E. Wickett, P.B. Duffy, and G. Rodrigue, A reduced grid for a parallel global ocean general circulation model, Ocean Modelling, 2, 85-107, 2000.

T. Guilderson, K. Caldeira, and P. Duffy, Radiocarbon as a diagnostic tracer in ocean and carbon cycle modeling, Global Biogeochemical Cycles, 14, 887-902, 2000.

J. Bell, P. B. Duffy, C. Covey, and L. Sloan, Analysis of Temperature Variability in Sixteen Climate Model Simulations, Geophysical Research Letters, 27, 261-264, 2000.

P. B. Duffy, J. Bell, C. Covey, and L. Sloan, Effect of flux adjustments on temperature variability in coupled models, Geophysical Research Letters., 27, 763-766, 2000.

K. Caldeira and P.B. Duffy, The role of the Southern Ocean in uptake and storage of anthropogenic carbon dioxide, Science, 287, 620-622, 2000.

A.J. Weaver, P. B. Duffy, M. Eby, and E.C. Wiebe, On the evaluation of ocean and climate models using present-day forcing, Atmosphere-Ocean, 38, 271-201, 2000.

P. B. Duffy, M. Eby, and A.J. Weaver, Effects of Sinking of Salt Rejected During Formation of Sea Ice on Results of a Global Ocean-Atmosphere-Sea Ice Climate Model, Geophys. Res. Lett., 26, 1739-1742, 1999.

M.I. Hoffert, K. Caldeira, C. Covey, P.B. Duffy, B. Santer, Solar variability and the Earth's climate, Nature, 401, 764-764, 1999.

P. B. Duffy and K. Caldeira, Sensitivity of Simulated Salinities in a Three-Dimensional Ocean General Circulation Model to Vertical Mixing of Destabilizing Surface Fluxes, Climate Dynamics, 15, 81-88, 1999.

B. Govindasamy, M. F. Wehner, C. R. Mechoso, and P. B. Duffy, The Influence of a Land Surface Scheme on Simulated Climate by LLNL/UCLA AGCM, Global and Planetary Change, 20, 67-86, 1999.

K. Caldeira, G. H. Rau, and P. B. Duffy, Predicted oceanic degassing of radiocarbon and increase in atmospheric radiocarbon content, Geophys. Res. Lett.., 25, 3811-3814, 1998.

K. Caldeira, and P. B. Duffy, Sensitivity of simulated CFC-11 distributions in a global ocean model to the treatment of salt rejected during sea-ice formation, Geophys. Res. Lett, 25, 10031006, 1998.

Wehner, M.F., P.G. Eltgroth, A.A. Mirin, P.B. Duffy, K.G. Caldeira, J.H. Bolstad, H. Wang, C.M. Matarazzo, U.E. Creach, 1997, Comprehensive Climate System Modeling on Massively 
Parallel Computers, in Mission Earth: Modeling and Simulation for a Sustainable Global System, edited by M.G. Clymer and C. R. Mechoso, the Society for Computer Simulation International, 37-42, 1998.

P. B. Duffy, and K. Caldeira, Sensitivity of Simulated Salinity in a Three-dimensional Ocean Model to Upper-Ocean Transport of Salt From Sea-Ice Formation,Geophys. Res. Lett. , 24, 1323-1326, 1997.

P. B. Duffy, K. Caldeira, J. Selvaggi, and M. Hoffert, Effect of Subgrid Scale Mixing Parameterizations on Simulated Distributions of Natural ${ }^{14} \mathrm{C}$, Temperature, and Salinity in a Three-Dimensional Ocean General Circulation Model, J. Phys. Oceanogr, 27, 498-523, 1997.

G. Perry. P. B. Duffy, and N. Miller, An Extended Dataset of River Discharges for Validation of Climate Models, J. Geophys. Res., 101, 21,339-21,349, 1996.

P. B. Duffy, D. Eliason, A. J. Bourgeois, and C. Covey, Simulation of Bomb Radiocarbon in Two Ocean General Circulation Models, J. Geophys. Research, 100, 22,545-22,565, 1995.

P. B. Duffy, and K. Caldeira, A Three-Dimensional Model Calculation of Ocean Uptake of Bomb ${ }^{14} \mathrm{C}$ and Implications for the Global Budget of Bomb ${ }^{14} \mathrm{C}$, Global Biogeochemical Cycles., 9, 373-375, 1995.

P. B. Duffy, P. Eltgroth, A. J. Bourgeois, and K. Caldeira, Effect of Improved Subgrid Scale Transport of Tracers on Uptake of Bomb Radiocarbon in the GFDL Ocean General Circulation Model, Geophysical Review Letters, 22, 1065-1068, 1995.

A. A. Mirin, J. J. Ambrosiano, J. H. Bolstad, A. J. Bourgeois, J. C. Brown, B. Chan, W. P. Dannevik, P. B. Duffy, P. G. Eltgroth, C. Matarazzo, and M. F. Wehner, Climate System Modeling using a Domain and Task Decomposition Message-Passing Approach, Computer Physics Communications., 84, 278-296, 1994.

M. Klapisch, P. B. Duffy, and W. H.Goldstein, A Monte Carlo Model of Complex Spectra for Opacity Calculations, Zeitschrift fur Physik D - Atoms, Moecules, and Clusters, 21, S185S186, 1991.

P. B. Duffy, M. Klapisch, J. Bauche, C. Bauche-Arnoult, Monte Carlo Calculations of Complex Spectra for Opacity Calculations, Phys. Rev. A., 44, pp. 5715-5724, 1991.

J. Bauche, C. Bauche-Arnoult, J. F. Wyatt, P. Duffy, and M. Klapisch, Simulation of Atomic Transition Arrays for Opacity Calculations, Phys. Rev. A., 44, pp. 5707-5714, 1991.

P. B. Duffy, E. F. Erickson, M. R. Haas and J. R. Houck, Far Infrared Spectroscopy of Star Formation Regions in M82, Astrophysical Journal, 315, p. 68, 1986.

P. J. Viscuso, G. J. Stacey, M. Harwit, M. R. Haas, E. F. Erickson, and P. B. Duffy "Observation of Far Infrared Transitions between Excited States of $\mathrm{OH}$ in Orion," Astrophysical Joumal, 296, p. 149, 1985.

P. B. Duffy, E. F. Erickson, M. R. Haas, and J. R. Houck, Far Infrared Spectroscopy of [OIII] in M82, NASA Conference Publication \#2353, p. 298, 1985.

J. M. Wilcox, P. B. Duffy, K. H. Schatten, L. Svalgaard, P. S. Scherrer, W. O. Roberts, and R. Olson, Interplanetary Magnetic Field Polarity and the Size of Low Pressure Troughs Near 180 Degrees West Longitude, Science, 204, p. 60, 1979. 


\section{DESCRIPTION OF FACILITIES AND RESOURCES}

No major equipment will need to be purchasesd to complete the proposed work. Access to DOE (NERSC) computing resources will be very important to this project, and will be negotiated if the proposal is funded.

We anticipate access to LLNL massively parallel institutional computing resources. Other computing resources involve desktop and laptop computers. 
PROPOSAL FOR LAB 02-07: EVALUATION OF CLOUD PARAMETERIZATION

\section{LETTERS OF SUPPORT}




\section{Lawrence Livermore National Laboratory}

April 15, 2002

Dear Bala,

I am writing to confirm my intent to consult with you on your proposed ARM research project entitled 'Evaluation of Cloud Parameterizations in a High Resolution Atmospheric General Circulation Model Using ARM Data'. Your proposed work provides an important bridge between the climate model development efforts at NCAR and the ARM data.

Good luck in the ARM proposal process.

Sincerely,

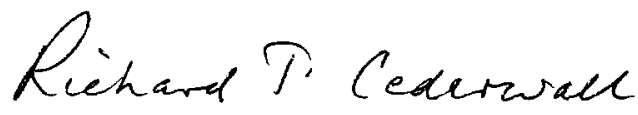

Richard T. Cederwall

Co-Chair, ARM Cloud Parameterization and Modeling Working Group 


\author{
NATIONAL CENTER FOR ATMOSPHERIC RESEARCH \\ P.O. Box 3000 - Boulder, Colorado 80307-3000 \\ James Hack・jhack@ncar.ucar.edu \\ Telephone: (303) 497-1387 - Fax: (303) 497-1324
}

April 15, 2002

Dr. Bala Govindasamy, PI

Research Scientist

Atmospheric Science Division

Lawrence Livermore National Laboratory

Livermore, CA 94550

Dear Bala:

This letter is to confirm my intention to participate in an informal consulting capacity on your project to evaluate cloud parameterizations in a high-resolution global atmospheric general circulation model.

Regards,

James J. Hack

Senior Scientist

Head, Climate Modeling Section 